DONALD S. KENKEL

Pennsylvania State University

D A V I D C . R I B A R

Pennsylvania State University

\title{
Alcohol Consumption and Young Adults' Socioeconomic Status
}

IN THE PAST FIFTEEN years the consumption and abuse of alcohol became matters of intense public concern. By the end of the 1980s, the federal government and many state governments had increased excise taxes on alcohol. The federal government began to require manufacturers to place warning labels on alcoholic beverage containers; the state governments (with some federal pressure) set their legal minimum drinking ages at a uniform twenty-one years. This surge of government activity may not be over. Policy initiatives still under consideration include further tax increases, requirements for sterner warning labels, mandated insurance coverage of alcoholism treatment, and restrictions on alcohol advertising, especially advertising targeted at young drinkers.

Advocates of new policies often point to estimates of the economic costs of alcohol abuse; in 1990 alcohol abuse and dependence imposed an estimated $\$ 98.6$ billion in costs on the U.S. economy. ' Key components of the economic cost results have been a series of controversial estimates that alcohol abuse substantially reduces productivity and hence earnings. ${ }^{2}$

This paper was presented at the December 1993 Microeconomics Panel Meeting for the Brookings Papers on Economic Activity. The authors thank the discussants, Phil Cook and Sam Peltzman, for their helpful comments. The authors also thank Eric Bond, Keith Crocker, Peter Reiss, Mark Roberts, David Shapiro, Mark Wilhelm, Clifford Winston, and the conference participants.

1. See Rice (1993), who updated the estimate for 1985 by Rice and others (1990).

2. Some of the controversy stems from a study by Harwood and others (1984) showing a negative effect of alcohol abuse on household income. Disturbingly, using the same data from the 1979 National Alcohol Survey, Heien and Pittman (1989) were unable to replicate these results. Rice and others (1990, pp. 193-95) revisited the controversy and attempted to replicate the Harwood model using the 1984 National 
In the most recent economic cost study, estimated lost productivity of workers suffering from alcohol problems (morbidity) accounted for $\$ 36.6$ billion in 1990 , more than a third of the total costs of $\$ 98.6$ billion. $^{3}$ The size of this number, and its frequent use in policy debates, motivate us to examine more closely the socioeconomic consequences of alcohol use. In addition to the policy interest, drinking behavior represents a situation where individuals' consumption choices intersect with their health and socioeconomic status, posing intriguing questions in several areas of applied microeconomics.

This paper uses unique data on young adults to explore how alcohol consumption affects earnings, labor supply, and marriage. Data from the National Longitudinal Survey of Youth (NLSY) enable us to isolate unobserved family- and individual-specific effects not captured in previous studies. We focus on these effects because alcoholism research shows there may be important family background and personality variables that jointly cause alcohol problems and socioeconomic status. Recent economic research suggests another line of inquiry: alcohol consumption and earnings may be simultaneously determined. To address this possibility, we develop instrumental variables to explain alcohol consumption. Our primary goal is to see whether the new information we develop changes or improves economic estimates cited in policy debates.

When we estimate benchmark models similar to earlier studies, we replicate both some standard findings and puzzles. For example, estimates from ordinary least squares (OLS) regression models that include only a standard set of explanatory variables imply that men with alcohol abuse or dependence earn about 5 to 10 percent less than men without alcohol problems. However, the corresponding results for women show a 10 percent earnings increase associated with alcohol abuse or dependence. Next, we estimate a series of models that address several of the empirical problems surrounding the relationship between alcohol use and socioeconomic status. These models produce a range of sometimes conflicting results, an outcome that is not altogether surprising given the strengths and weaknesses of the various estimation methods. The effects of alcohol

Alcohol Survey. They were also unable to find a statistically significant negative effect of alcohol abuse.

3. See Rice (1993). A much earlier reference is Fisher (1926, pp. 157-61). He estimated that Prohibition, if effective, would increase national productivity by at least $\$ 3.3$ billion (about $\$ 27$ billion when expressed in current dollars). 
consumption on earnings remain difficult to pin down. The results essentially rule out a large negative effect of alcohol use on labor supply for young men. The relationship between alcohol consumption and the labor supply of young women is harder to characterize. In fact, the consequences of alcohol consumption appear to be different for men and women. Finally, estimates from the different empirical approaches consistently show a negative effect of alcohol problems on marital status for both men and women.

The remainder of this paper is organized as follows. After providing some background to illustrate the current scope of alcohol problems, we review the general framework used to explain how these problems may affect socioeconomic status. Based on medical and economics research findings, we then identify several important econometric issues that complicate estimation, and we illustrate these problems using a simple stylized model. Alternative remedial econometric approaches, and some potential pitfalls, are also discussed. Following a description of the data and variables used in the analysis, the results are presented. The last two sections of the paper discuss policy implications and conclusions.

\section{Background}

Recent national estimates show that both alcohol consumption and alcohol problems are common in the United States. Roughly two-thirds of the adult population in this country consume some alcohol on a regular or at least occasional basis. While most are light or moderate drinkers, as many as 10 percent of adults may be problem drinkers, depending upon the exact definition used. ${ }^{4}$ The third edition of the American Psychiatric Association's Diagnostic and Statistical Manual of Mental Disorders (DSM-III) defines two categories of problem drinking: alcohol abuse and alcohol dependence. Using these definitions, the

4. See USDHHS (1990, chap. 2) for a description of patterns and trends in alcohol use and abuse. In the literature there is no generally agreed upon precise definition of the terms problem drinking or even alcoholism. Arguing against the classic disease concept of alcoholism, Fingarette (1988) proposed calling this level of consumption simply heavy drinking. Following convention, we use the terms problem drinking, alcoholism, and heavy drinking as they have been used in previous research, without trying to precisely define them. In the empirical analysis we precisely define our measures of alcohol abuse, dependence, and heavy drinking. 
national prevalence estimate for 1988 is that 8.63 percent of adults, or over 15 million Americans, have diagnoses of either alcohol abuse or dependence. ${ }^{5}$ In the DSM-III alcohol abuse is defined as a maladaptive pattern of alcohol use, and it is detected for the national prevalence estimates by self-reports of continued drinking despite a persistent social, occupational, psychological, or physical problem related to drinking or by drinking in situations where drinking is physically hazardous. ${ }^{6}$ A diagnosis of alcohol dependence requires self-reports of symptoms that meet at least three of the following DSM-III criteria: tolerance; withdrawal; drinking to relieve or avoid withdrawal symptoms; drinking larger amounts than intended; spending a great deal of time drinking; continued drinking despite problems; neglected responsibilities or obligations; or impaired control. The more serious diagnosis of dependence is actually more prevalent as defined in this way (only 2.38 percent are diagnosed with abuse, compared with 6.25 percent with dependence). Alcohol abuse and dependence are much more prevalent among men (13.35 percent) than women (4.36 percent). For both genders the prevalence is highest among people eighteen to thirty years old, the age group represented in the NLSY. In this age group almost a quarter of men and about 10 percent of women suffer from alcohol abuse or dependence.

Linking alcohol problems and socioeconomic outcomes is a logical extension of human capital models of the determinants of earnings. ${ }^{7}$ Given a well-functioning labor market, more productive workers will earn more. Alcohol problems may have both short-run and long-run effects on productivity. In the short run alcohol problems may cause increased absenteeism and lower productivity on the job due to the aftereffects of heavy drinking. In the long run alcohol problems may reduce productivity and wages indirectly through the worker's health capital, schooling capital, and labor market experience. Most previous analyses implicitly focused on the short-run consequences.

Early research on economic costs treated alcohol abuse akin to a disease randomly striking some portion of the population. These studies estimated models in which current earnings or income were specified

5. See Grant and others (1991, p. 95).

6. Self-reported drunk driving on more than one occasion is sufficient for a diagnosis of alcohol abuse.

7. Some standard references are Mincer (1974) and Becker (1975). 
to be a function of exogenous current drinking. Consider a stylized empirical model of the form

$$
Y_{i}=\alpha+\beta A_{i}+u_{i},
$$

where $Y_{i}$ represents the natural logarithm of individual $i$ 's earnings, $A_{i}$ is a measure of alcohol problems, and $u_{i}$ represents unobserved variation in the determinants of $Y_{i}$. Studies usually have included other characteristics of the individual as explanatory righthand side variables; for purposes of exposition, let these terms be subsumed into the constant term $\alpha$.

In specification 1 the coefficient on the alcohol variable gives the percentage change in earnings associated with a change in alcohol status. Relying on ordinary least squares analyses of equations similar to equation 1 , researchers have interpreted negative estimates of $\beta$ as evidence that alcohol abuse causes lower earnings. Studies of the economic costs of alcohol abuse based on the OLS methodology have generally concluded that problem drinking causes earnings losses in the range of 10 to 20 percent. $^{8}$

There is no strong consensus in the existing empirical literature on the statistical significance or sign of $\beta$. While the failure to find statistically significant negative effects is important, new results reportedly show that users of alcohol and illicit drugs earn more than nonusers. ${ }^{9}$ Positive effects are not implausible: recent medical and epidemiologic evidence suggests that moderate use of alcohol may improve health, so moderate use may also increase productivity. ${ }^{10}$ The different results may reflect the different phenomena examined by researchers-moderate versus problem drinking. It has been difficult to resolve the controversy because few data sets contain information on both alcohol use and labor market outcomes. Several of these data sets were collected

8. See Berry and Boland (1977); Harwood and others (1984); and Rice and others (1990). Because of data availability, the first two of these studies estimated the relationship between alcohol problems and household income, not earnings.

9. The switching regressions model by Berger and Leigh (1988) suggested that moderate drinking had positive economic effects. Cook (1991) re-examined these data and concluded that Berger and Leigh's results were robust, but he did not find evidence that even heavy drinking has adverse effects on earnings. Kaestner (1991) reported results suggesting that users of illicit drugs earn more than nonusers.

10. For a recent review see the editorial by Shaper (1993) and related articles in the June 1993 American Journal of Public Health. 
to study alcohol problems, and they contain only very limited labor market measures. ${ }^{11}$

Empirical research originally emphasized the productivity effects of problem drinking, as evidenced by lower earnings or income. The scope of the inquiry can be broadened to address a number of related issues. First, since earnings depend on the wage rate and labor supply, the coefficient $\beta$ from equation 1 is the sum of the two corresponding elasticities. The effect of alcohol on labor supply, in turn, can be decomposed into its effect on labor force participation and its effect on hours worked conditional on participation. Studies that have isolated the effect of alcohol consumption on participation have yielded mixed results. ${ }^{12}$ Second, there is evidence that problem drinkers suffer additional socioeconomic consequences. Several studies find that alcoholics attain about one and a half years less schooling than do people without alcohol problems.$^{13}$ In one study alcoholics appeared to be 8 percentage points more likely to be separated, widowed, or divorced. ${ }^{14}$ Of concern by themselves, these outcomes provide additional channels by which problem drinking may reduce earnings. There is a growing consensus that these indirect channels may be nearly as important as the direct link between problem drinking and earnings; indeed, the indirect effects may account for almost one-half of the total effect of alcoholism on earnings. ${ }^{15}$ While not all of the indirect effects can be explored using the NLSY data, below we estimate the effects of alcohol problems on labor supply and marriage, as well as on earnings. ${ }^{16}$

11. For excellent critical reviews of the empirical literature, see Heien and Pittman (1989); Cook (1991); and Mullahy (1993). It is important to recognize that a number of recent studies (Mullahy and Sindelar 1989, 1991, 1993; and Rice and others 1990) have analyzed the Epidemiologic Catchment Area data, but it is not known yet if the same patterns will be found in other data sets.

12. The regression results by Benham and Benham (1982) showed no statistically significant relationship between alcoholism and employment, while Mullahy and Sindelar (1993) found that alcohol abuse or dependence was negatively and statistically significantly related to full-time work propensity.

13. See Mullahy and Sindelar (1989) and Benham and Benham (1982).

14. See Benham and Benham (1982, p. 210).

15. See Mullahy and Sindelar (1993).

16. It is difficult to study the effects of alcohol on educational attainment because many of the respondents to the NLSY had completed schooling prior to the survey panels that included questions on alcohol. Using the NLSY, Cook and Moore (1993) found evidence that alcohol problems decrease attainment of postsecondary schooling. 


\section{Problems, Solutions, and Potential Pitfalls}

In the spirit of Zvi Griliches, consider an extension of equation 1 in which earnings are a function not only of alcohol consumption but also of some unobserved or partially observed personal attribute, $C_{i}$, such that

$$
Y_{i}=\alpha+\beta A_{i}+\gamma C_{i}+u_{i}
$$

where $Y_{i}, A_{i}$, and $u_{i}$ are defined as before. ${ }^{17}$ Consider as well a standard model drawn from the economic and medical research literature in which $C_{i}$ is also a determinant of alcohol consumption. Specifically, let alcohol consumption be a function of observable background and contextual characteristics, $B_{i}$, the personal attribute, $C_{i}$, and other unobserved determinants, $e_{i}$, such that

$$
A_{i}=\pi B_{i}+\lambda C_{i}+e_{i} .
$$

The key feature of this model is that $C_{i}$ is a common determinant of both earnings and alcohol consumption. This specification is motivated by the observation that many personal and background factors associated with the development of alcohol problems plausibly have direct effects on productivity and earnings. For example, a description of the "pre-alcoholic home" is based on aspects of childhood environment related to subsequent adult alcoholism. ${ }^{18}$ Studies have consistently found that alcoholics are more likely than nonalcoholics to have been raised in a home with heightened marital conflict, inadequate parenting, and lack of child-parent contact. The parents of future alcoholics are also more likely to have been alcoholic, antisocial, or sexually deviant. In addition, depression and antisocial personality are so strongly associated with alcoholism that alcoholism has been considered a manifestation of these disorders rather than as a separate disorder. ${ }^{19}$ It seems reasonable that people with deficient family backgrounds or personality disorders may suffer socioeconomic disadvantage independent of whether they develop alcohol problems. ${ }^{20}$

17. See Griliches (1979).

18. See Zucker and Gomberg (1986).

19. See Hesselbrock (1986, pp. 44-49).

20. Related to this point, Benham and Benham (1982), Bartel and Taubman (1986), and Frank and Gertler (1991) have estimated that mental illness significantly decreases income or earnings. 
These considerations have clear econometric implications. An OLS regression of equation 2 that omits or fails to completely control for personal attributes yields a biased estimate of the effect of drinking. Under the assumption that $u_{i}$ and $e_{i}$ are uncorrelated, the relationship between the biased estimate, $\beta_{o L S}$, and the true effect, $\beta$, can be expressed

$$
\left(\beta_{o L S}\right)=\beta+\lambda \gamma \frac{\sigma_{C}^{2}}{\sigma_{A}^{2}},
$$

where $\sigma_{C}^{2}$ denotes the variance of $C_{i}$ and $\sigma_{A}^{2}$ denotes the variance of $A_{i}$. Continuing with the illustration of $C_{i}$ as representing a deficient family background or a personality disorder, we hypothesize that the independent effects of $C_{i}$ on earnings and alcohol consumption are negative and positive respectively (that is, $\gamma<0$ and $\lambda>0$ ). The uncorrected OLS estimate of $\beta$ would therefore be hypothesized to be negatively biased. Other possible interpretations are that $C_{i}$ represents unmeasured productivity or aspects of permanent income. In these cases hypotheses regarding the likely biases are less clear cut.

Models similar to equations 2 and 3 describe the effect of drinking on the other socioeconomic outcomes considered in this paper-hours worked and marital status. We again hypothesize that omitting the personal attribute measure $C_{i}$ results in an estimate of $\beta$ that is biased toward finding a more negative effect of drinking on hours worked and marital status. ${ }^{21}$

A number of potential methodological remedies address omitted variables bias. The most obvious remedy is to include a sufficiently rich set of personal attributes that either directly captures or indirectly proxies the effects of $C_{i}$. Our empirical analysis begins by examining results from a series of OLS regressions based on equations 1 and 2 that include increasingly detailed sets of personal controls. Although potentially biased, the OLS estimates are easily computed and comparable to previous research. Further, under plausible assumptions we can postulate signs for the likely biases ex ante. The practicality of this approach is limited by our difficulty in obtaining precise descriptions of personality problems and the quality of individuals' upbringing. Nevertheless,

21. Similar to our hypothesis, Zucker and Gomberg (1986) suggested that the parental conflict in the pre-alcoholic home may be part of the cause of the marital instability associated with adult alcoholism. 
comparisons of models that do and do not incorporate various personal characteristics may provide a rough indication of the potential severity of the bias.

The second, less direct, approach followed below compares siblings. If individuals' unobserved productive characteristics are entirely family-specific and identical across brothers and sisters, differencing equation 2 across siblings eliminates these factors and permits unbiased estimation of the effect of alcohol on socioeconomic status. This strategy is theoretically attractive and has clear relevance as a solution to controlling for upbringing in a "pre-alcoholic home." However, its usefulness is sensitive to the assumption of identical effects across family members. To the extent that siblings' upbringing and other relevant personal characteristics are not entirely identical, biases will remain. Moreover, if family members are more alike in unobserved determinants that affect only alcohol consumption than in determinants that affect both alcohol consumption and earnings, siblings' differences exacerbate the bias. Siblings' differences may also worsen biases associated with other econometric problems such as measurement error or endogeneity in $A_{i} \cdot{ }^{22}$

A related corrective strategy is to exploit the longitudinal nature of the NLSY and estimate individual fixed-effects models of the effect of drinking on socioeconomic status. As with the sibling difference models, longitudinal fixed-effects models offer the promise of removing omitted variables bias associated with unobserved family-specific effects. In addition, the longitudinal models will remove bias from any time-invariant person-specific effects. Unfortunately, caveats must still be invoked. Longitudinal differencing will not necessarily remove family-specific effects, if these effects vary over time. Also, in the presence of measurement error or endogeneity, longitudinal fixed-effects estimators may again exacerbate, rather than reduce, statistical biases. Finally, there is a practical problem: only a subset of the data on alcohol consumption and problem drinking is available longitudinally in the NLSY.

As the preceding discussion suggests, the econometric complexities in examining the socioeconomic consequences of alcohol consumption

22. See Griliches (1979, pp. S40-S44) for a more complete discussion of these issues. 
are not necessarily limited to omitted variables. Consider a case where there is reciprocal causality between drinking and earnings. In particular, rewrite equation 3 as

$$
A_{i}=\pi B_{i}+\delta Y_{i}+e_{i} .
$$

For purposes of discussion, let us ignore problems associated with $C_{i}$ and focus on the issues raised only by the simultaneity of $Y_{i}$ and $A_{i}$.

While equation 5 may appear to be ad hoc, it is in fact motivated by recent empirical and theoretical studies by economists. Simply appealing to demand theory, it would appear that overall alcohol consumption is likely to depend on income and earnings. The budget constraint may also influence heavier drinking, even if it is thought that heavy drinkers have little control over their behavior. Beyond this, the model of rational addiction suggests that it may be useful to view alcoholism as subject to standard economic forces. ${ }^{23}$

Estimates of the effect of alcohol on socioeconomic outcomes that neglect simultaneity are biased if the true model is as specified in equations 2 and 5. Assuming that $\gamma=0$ and $u_{i}$ and $e_{i}$ are uncorrelated, the relationship between the naive estimate, $\beta_{o L S}$, and the true $\beta$ is given by

$$
\left(\beta_{o L S}\right)=\beta+\frac{\delta}{1-\delta \beta} \frac{\sigma_{u}^{2}}{\sigma_{A}^{2}}
$$

where $\sigma_{u}^{2}$ denotes the variance of $u_{i}$. Under the assumption that the true effect of alcohol consumption on earnings is negative and that alcohol consumption is a normal good $(\delta>0)$, we would hypothesize that simultaneity results in an upward bias in $\beta_{o L s}$ and a corresponding understatement of the socioeconomic consequences of drinking. As-

23. For empirical evidence that heavy drinking and problem drinking respond to standard economic forces, see Cook (1981); Cook and Tauchen (1982); Kenkel (1991a, 1993); and Chaloupka, Saffer, and Grossman (1993). Grossman (1993) reviewed the theoretical and empirical issues regarding the application of the theory of rational addiction to alcohol use. A complete rational addiction model of alcohol use and abuse assumes that individuals balance the relative costs and benefits in deciding whether or not to consume alcohol. Current and future socioeconomic consequences can be included as costs of consumption, providing an additional reason why earnings may be a determinant of drinking behavior. 
sumptions drawn from more intricate rational addiction models result in more complicated predictions.

Models of the simultaneous determination of alcohol use and hours worked, and alcohol use and marital status, are similar to the earnings model described by equations 2 and 5 . While the hypothesized direction of simultaneity bias in the model of hours worked is the same as in the earnings model, income effects are less of an issue in explaining the relationship between alcohol consumption and marital status. Instead, marital status may be a determinant of drinking, in addition to the possibility that drinking reduces the probability of being (or staying) married.${ }^{24}$ For this case our assumption is that simultaneity results in a downward bias, so that simple models overestimate the negative effects of drinking on marital status.

Another econometric difficulty arises if alcohol consumption is imperfectly measured. This paper and most previous studies rely on selfreported drinking behavior and drinking problems. The NLSY drinking data used below come from thirty-day retrospective reports and hence are subject to recall error. The different periodicities of the drinking data (monthly) and outcomes data (annual) also increase the chances of measurement error. In a standard OLS regression the presence of random measurement error biases the estimated effect of drinking on socioeconomic status toward zero. Such bias becomes an even more severe problem in regressions that use sibling or longitudinal differences to control for fixed effects. ${ }^{25}$

One way of viewing all of the econometric problems described above is that the measure of alcohol consumption in equations 1 and 2 is effectively correlated with the error term, $u_{i}$. Subject to the availability of appropriate identifying measures, instrumental variables (IV) techniques can be used to obtain consistent estimates of the consequences of drinking. This paper employs an IV methodology that has been successfully applied in previous studies of the effects of youth problem behavior on subsequent socioeconomic status. ${ }^{26}$ Estimation of the si-

24. Miller-Tutzauer, Leonard, and Windle (1991) found evidence that entry into marriage is associated with reductions in drinking and heavy drinking.

25. See Griliches (1979) and Griliches and Hausman (1986).

26. See Kaestner (1991); Mullahy and Sindelar (1992); Cook and Moore (1993); and Ribar (1993). 
multaneous models is complicated because several of our drinking and outcome measures are qualitative or limited dependent variables. Consequently, we adopt a three-stage minimum distance estimation procedure. ${ }^{27}$

To sum up, each of the aforementioned problems-omitted variables, simultaneity, and imperfectly measured consumption data-is a relevant concern. Therefore, we employ several alternative econometric techniques. The promise of sibling and longitudinal difference models lies in the possibility of eliminating, or at least reducing, bias associated with omitted family- and individual-specific effects. Unfortunately, to the extent that simultaneity is a problem, the net effect may be that differencing removes one bias just to uncover (or, worse yet, exacerbate) another. But if family- or individual-specific effects account for a large part of the unobserved variation in socioeconomic status, sibling and longitudinal comparisons may actually reduce biases associated with both omitted variables and simultaneity. ${ }^{28}$ Use of IV techniques offers the promise of consistent estimates of the consequences of drinking, but serious efficiency problems may arise if the instruments have only modest explanatory power.

\section{Data}

The primary data used in this analysis come from the 1979-90 panels of the National Longitudinal Survey of Youth. The NLSY contains detailed economic and demographic information for 12,686 individuals who were fourteen to twenty-one years old in 1979. Annual data on work behavior, incomes, and marital status are available for each individual in the survey. Retention through the 1990 panel is roughly 90 percent. Another important though often overlooked feature of the NLSY is that interviews were conducted with all of the fourteen- to

27. The three-stage procedure is similar to the methodology outlined by Amemiya (1978). The models are estimated using version 2.0 of the MECOSA program system; see Schepers and Arminger (1992). Structural estimators based directly on Amemiya's procedure were implemented by Mullahy and Sindelar (1992) in their study of the employment consequences of problem drinking.

28. In particular, longitudinal fixed-effects estimators should reduce simultaneity bias implied by a rational addiction model of the joint determination of alcohol abuse and earnings. 
twenty-one-year-olds living in each of the surveyed households in 1979. Household and relationship identifiers from these data can be used to form reasonably large data sets of siblings. Our analysis focuses on same-gender sibling pairs; for each sex, the raw NLSY data contain approximately 900 pairs. ${ }^{29}$

The NLSY also contains detailed information that allows us to create four alternative measures of alcohol consumption and problem drinking. Problem drinking is an inherently difficult concept to measure empirically, and previous research has demonstrated that the estimated impacts of alcohol consumption on earnings can be sensitive to the alcohol measure used. ${ }^{30}$ The analysis in this paper concentrates on drinking behavior and socioeconomic outcomes in 1989, the only panel in the NLSY that included questions corresponding to the DSM-III diagnostic criteria for alcohol abuse and dependence. Our analysis uses self-reported answers to these questions to form dummy variables indicating whether individuals were dependent upon or abusing alcohol. ${ }^{31}$ These diagnostic measures should be useful indicators of two different manifestations of problem drinking, but they do not measure other potentially important differences in alcohol consumption. To capture these differences, we create two additional measures using information on individuals' drinking habits in the preceding thirty days. The survey contains categorical data on the number of times during the past month that individuals consumed six or more drinks on a single occasion (possible responses are zero, one, two to three, four to five, six to seven, eight to nine, or ten or more times). This categorical variable is

29. In households with three or more siblings of the same sex, our analysis selects two siblings at random.

30. In an extremely useful illustrative exercise, Sindelar (1993, pp. 212-18) estimated the effects of alcohol consumption on income using ten alternative measures of alcohol use available in data from the 1988 National Health Interview Survey. As might be suspected from the conflicting results of previous studies, the estimated coefficients on the alcohol measures varied not only in magnitude but in sign. As Sindelar (1993, p. 216) pointed out, "The conclusions one could reach on the effect of alcohol on income do depend on the measure of alcohol used."

31. Answers to a similar set of questions were used by Grant and others (1991) to estimate national prevalence rates and by Mullahy and Sindelar (1992) to examine the economic consequences of problem drinking. As with the analyses by Mullahy and Sindelar, our definitions of abuse and dependence do not use information specifically related to work/alcohol problems. Data on alcohol-related employment problems could introduce spurious correlation into the analysis of drinking and socioeconomic status. 
used as our measure of heavy drinking, and it will reflect consumption that is potentially problematic whether or not the individual reports alcohol problems.$^{32} \mathrm{~A}$ continuous variable recording the number of days on which people had at least one drink is used as a general measure of alcohol consumption. Particularly when used in combination with one of the other alcohol measures, this measure helps us separate the effects of moderate and problem drinking. Finally, because a young adult's self-reported alcohol use may not be reliable when others (for example, parents) are present, we incorporate a variable indicating the presence of people other than the interviewer and respondent during the interview as a control for accuracy. ${ }^{33}$

The means and standard deviations of the alcohol measures and the other variables used in the empirical analysis are reported in appendix A. The NLSY sample means for alcohol dependence and abuse are very close to previous national prevalence estimates for the same age group: 20 percent of the men and 8 percent of the women are diagnosed with alcohol dependence, while 15 percent of the men and 5 percent of the women are diagnosed as alcohol abusers. ${ }^{34}$ To show how the four alcohol measures compare, table 1 provides means for heavy drinking and the number of days of drinking by gender and problem drinking status. As should be expected, the subsamples diagnosed as alcohol dependent or alcohol abusers engage in more heavy drinking and more frequent drinking. For example, men diagnosed as alcohol abusers engaged in almost four times as much heavy drinking as nonabusers. Part of the difference reflects abstainers, but even compared with nonabusers who drank in the past month, abusers engaged in more than twice as much heavy drinking. In terms of the amount of heavy drinking and frequency of drinking, respondents diagnosed as dependent appear sim-

32. When used as an explanatory variable in the OLS and fixed-effects models, the categorical heavy drinking measure is converted to a continuous equivalent using the midpoints of the variable's scale. In the simultaneous equations estimates, heavy drinking is modeled as an ordered categorical variable with known thresholds.

33. In an analysis of the 1984 and 1988 waves of the NLSY, Hoyt and Chaloupka (1993) found that the presence of a parent is associated with statistically significant reductions in reported use and frequency of alcohol, while the presence of a friend is associated with higher reported use.

34. See Grant and others (1991). It should be noted that alcohol abuse and alcohol dependence are not mutually exclusive categories and that there is no necessary ordering. That is, it is possible to be diagnosed as dependent but not an abuser, or as an abuser who is not dependent. 
Table 1. Mean Alcohol Consumption by Gender and Problem Drinking Status

\begin{tabular}{lccccccc}
\hline & & \multicolumn{2}{c}{ Men } & & \multicolumn{2}{c}{ Women } \\
\cline { 3 - 4 } \cline { 6 - 7 } Category & $N$ & $\begin{array}{c}\text { Heavy } \\
\text { drinking }\end{array}$ & $\begin{array}{c}\text { Days drinking } \\
\text { per month }\end{array}$ & & $\begin{array}{c}\text { Heavy } \\
\text { drinking }\end{array}$ & $\begin{array}{c}\text { Days drinking } \\
\text { per month }\end{array}$ \\
\hline Full sample & 4,604 & 1.98 & 6.35 & 4,910 & 0.63 & 2.79 \\
& & $(3.08)$ & $(7.86)$ & & $(1.74)$ & $(5.00)$ \\
Nonabusers & 3,924 & 1.40 & 5.17 & 4,640 & 0.44 & 2.39 \\
& & $(2.56)$ & $(6.98)$ & & $(1.38)$ & $(4.47)$ \\
Nonabusers who & 2,616 & 2.10 & 7.75 & 2,335 & 0.88 & 4.75 \\
$\quad$ drank in past month & & $(2.88)$ & $(7.28)$ & & $(1.85)$ & $(5.34)$ \\
Abusers & 680 & 5.36 & 13.18 & & 270 & 3.77 & 9.61 \\
& & $(3.63)$ & $(9.09)$ & & $(3.41)$ & $(7.89)$ \\
Nondependents & 3,689 & 1.16 & 4.64 & 4,499 & 0.36 & 2.14 \\
& & $(2.25)$ & $(6.46)$ & & $(1.20)$ & $(4.06)$ \\
Nondependents who & 2,318 & 1.79 & 7.19 & 2,194 & 0.73 & 4.38 \\
$\quad$ drank in past month & & $(2.59)$ & $(6.81)$ & & $(1.63)$ & $(4.90)$ \\
Dependents & 915 & 5.32 & 13.26 & 411 & 3.57 & 9.91 \\
& & $(3.66)$ & $(9.11)$ & & $(3.30)$ & $(7.94)$ \\
\hline
\end{tabular}

Source: Figures based on 1989 data from the NLSY. Standard deviations appear in parentheses.

ilar to those diagnosed as abusive. While women engage in less heavy drinking and less frequent drinking than men, the relationships between these measures and the problem drinking indicators show patterns similar to the patterns for men.

In addition to the consumption and problem drinking data, the NLSY contains several indicators of socioeconomic status. Our analysis considers three specific outcome measures - total annual individual earnings, total annual labor market hours, and marital status. Annual earnings and labor supply data for calendar year 1989 have been taken from the 1990 survey; marital status is recorded as of the 1989 survey date. Observations with missing or censored outcomes data have been dropped from the sample. In constructing each of the dollar-denominated economic variables, nominal amounts have been converted to constant 1982 dollars using the Personal Consumption Expenditure deflator.

A final reason for using the 1989 data is that by that year almost every sample member had completed his or her schooling. All of our empirical models exclude individuals who were currently enrolled in 
school. This is a less severe restriction in 1989 than in earlier panels of the NLSY. ${ }^{35}$

Measures of earnings, labor market hours, marital status, interview status, heavy drinking, and general alcohol consumption similar to the 1989 variables can also be constructed from the 1982-85 and 1988 panels. ${ }^{36}$ The paper's longitudinal fixed-effects models use outcomes information from 1985 and 1988 along with the 1989 data. Where possible, the robustness of our reported results has been examined using data from alternative time periods.

From the detailed information available in the NLSY, we constructed a series of personal descriptors to be used as controls for contextual and background factors. Year of birth is used as a control for age and cohort effects. Indicator variables for African and Latino origin are incorporated as controls for differences in economic opportunities as well as cultural differences in the determinants of drinking behavior and socioeconomic attainment. A variable indicating frequent attendance at religious services as of 1979 captures variation in personal values.

Included among the productivity and human capital controls in our study are contemporaneous (1985, 1988, and 1989) dummy indicators for health problems that limited individuals' ability to work. Additional human capital differences are captured by general measures of educational attainment (dummy variables for high school and college completion) as well as by results from a standardized intelligence test, the Armed Forces Qualification Test (AFQT) portion of the Armed Services

35. In $1989,5.6$ percent of the available NLSY sample were excluded from our analysis because of their enrollment status. For the longitudinal fixed-effects models, we use data from as early as 1985 . when roughly 11 percent of the sample were enrolled in school. All of the results reported in this paper have been re-estimated retaining enrollees and found to be robust to the sampling restrictions. These results are available upon request from the authors.

36. The 1982-85 panels also contain information on consumption of specific alcoholic beverages-beer, wine, and distilled spirits-in the past week. Research has suggested that there are systematic differences between "typical" drinkers of different alcoholic beverages (Klein and Pittman, 1990). For example, beer drinkers typically drink heavily, and wine drinkers tend to drink in moderation. Although distinguishing the type of alcoholic beverage consumed is potentially useful, this same research has found that drinkers in the NLSY age group mainly consume beer. This is borne out in the NLYS data for 1982-85. Of people who reported drinking in the past week, roughly three-quarters reported drinking beer, while only about one-quarter reported drinking any wine, and somewhat under half reported drinking any distilled spirits. 
Vocational Aptitude Battery, which was administered to survey participants in $1980 .{ }^{37}$

Several variables are used to account for variation in family background and upbringing. The paper includes two measures of family structure-number of siblings and a dummy variable for residing in a nonintact family at age fourteen-as rough controls for household economic circumstances, parental supervision, and family values. Information on parents' educational attainment is also used to capture variation in family economic resources, values, and expectations; for each parent the education variables consist of continuous measures of completed schooling and dummy indicators for missing data. A dummy variable flagging whether household members subscribed to magazines is taken as an additional measure of family encouragement toward reading and schooling and general household resources.

Retrospective family alcoholism data are also available in the NLSY. Respondents in the 1988 panel were asked to identify alcoholic relatives and the number of years, if any, they resided with those relatives. From these data we constructed three variables-dummies for an alcoholic father or stepfather, alcoholic mother or stepmother, or other distant (nonsibling, nonresident) alcoholic relative. Having parents or other relatives who are alcoholics is taken to indicate a possible genetic or attitudinal predisposition toward problem drinking. Alcoholic parents may also signal socioeconomic disadvantage in an individual's upbringing.

Longitudinal state- and county-level economic and institutional measures have been collected separately and used to supplement the NLSY data. Local economic descriptors include county-level measures of the unemployment rate, employment composition (percentage of all workers employed in manufacturing), and per capita total personal income. The unemployment data are available directly from the NLSY. The other county-level economic variables have been obtained from the Regional Economic Information System of the Bureau of Economic Analysis. The paper's policy measures include the price of beer (the

37. Roughly 94 percent of the NLSY sample completed the standardized test. Individuals who were unavailable for interview in 1980 or had been previously exposed to the test account for most of the nonresponse (Center for Human Resource Research, 1990). 
beverage of choice in the NLSY age group) and the percentage of individuals in the state who reside in dry counties. ${ }^{38}$

\section{Results}

The first step in the empirical analysis is to estimate models similar to those used in earlier studies and attempt to replicate their results.

\section{Benchmark Models}

Table 2 reports separately for men and women the estimated effects of alternative measures of drinking on the three socioeconomic outcomes-earnings, labor supply, and marriage. In table 2 the continuous earnings and hours outcomes are specified as natural logarithms and estimated using OLS. Marriage is modeled as a binary outcome and estimated using maximum likelihood probit.

The regressions for each drinking and outcome combination have been estimated using alternative sets of control variables. The first reported specification for each model uses a basic set of controls (age, ethnicity, religiousness, local economic conditions, and health status) that have been included in other studies. Estimates from the basic specifications appear in the first row under each of the outcome headings in table 2. Consistent with previous research, the overall results for men point to significant consequences from drinking. In particular, the estimates indicate that alcohol dependence reduces men's annual earnings by 9.8 percent and that alcohol abuse reduces earnings by 6.3 percent. Each occurrence of heavy drinking in the basic model reduces men's annual earnings by 1.7 percent. The impact of engaging in as much heavy drinking as the average alcohol dependent or abusing man (from table 1, about 5.3 instances) is a 9.01 percent decrease in earnings. While the measures of problem and heavy drinking appear to yield very similar results, occurrences of general alcohol consumption have no noticeable effect on earnings. This is not surprising, since the measure of general alcohol consumption makes less of a distinction between moderate and problem drinking.

38. The alcohol policy variables were made available by Paul Gruenewald of the Prevention Research Center, Berkeley, California. 
In the basic model alcohol appears to have less effect on men's hours of work than on their earnings. While occurrences of heavy drinking are estimated to reduce labor supply by a small but statistically significant amount (0.9 percent), the effects of alcohol dependence, abuse, and general consumption are negligible. Stronger negative effects are found for marriage. The calculated marginal effects of alcohol dependence and abuse give a rough approximation of the magnitude of the relationships. ${ }^{39}$ These calculations suggest that alcohol dependence and abuse reduce the likelihood of marriage by 15 and 12 percent respectively. Occurrences of heavy drinking and general consumption are estimated to decrease the men's chances of being married by 2 and 0.6 percent respectively.

In contrast to the seemingly reasonable results for men, the results for women are somewhat puzzling and more suggestive of econometric complications. Using the basic set of controls, we can see that alcohol abuse and dependence each appear to increase women's earnings by more than 10 percent. General alcohol consumption is also estimated to have positive earnings effects for women. The only result to suggest a negative effect is the coefficient on heavy drinking. Though statistically insignificant, it is nearly identical to the coefficient for men. Similar to the men's results, alcohol consumption has little effect on women's labor supply. With respect to marital status, the negative effects of drinking for women are two to three times larger than the effects for men.

Estimates from models that incorporate controls for family background and ability are listed in the second and third rows under each heading in table 2. Differences in estimates across specifications indicate that omitted variables bias is present in some of our initial models. While most of the changes are consistent with expectations, the new results do little to resolve the differences across gender. Specifically, the addition of background variables diminishes the estimated earnings effects for men and women. However, when ability variables are included, the negative earnings effects for men decrease in size, while

39. The marginal effect of alcohol on marriage is calculated as $\phi(\hat{m}) \beta$, where $\phi(\hat{m})$ is the standard normal density function evaluated at the predicted latent marriage index, and $\beta$ is the probit coefficient on drinking. Caution should be applied in interpreting the result since the marginal effect in the probit model varies at different points in the sample (that is, for different groups of individuals). 


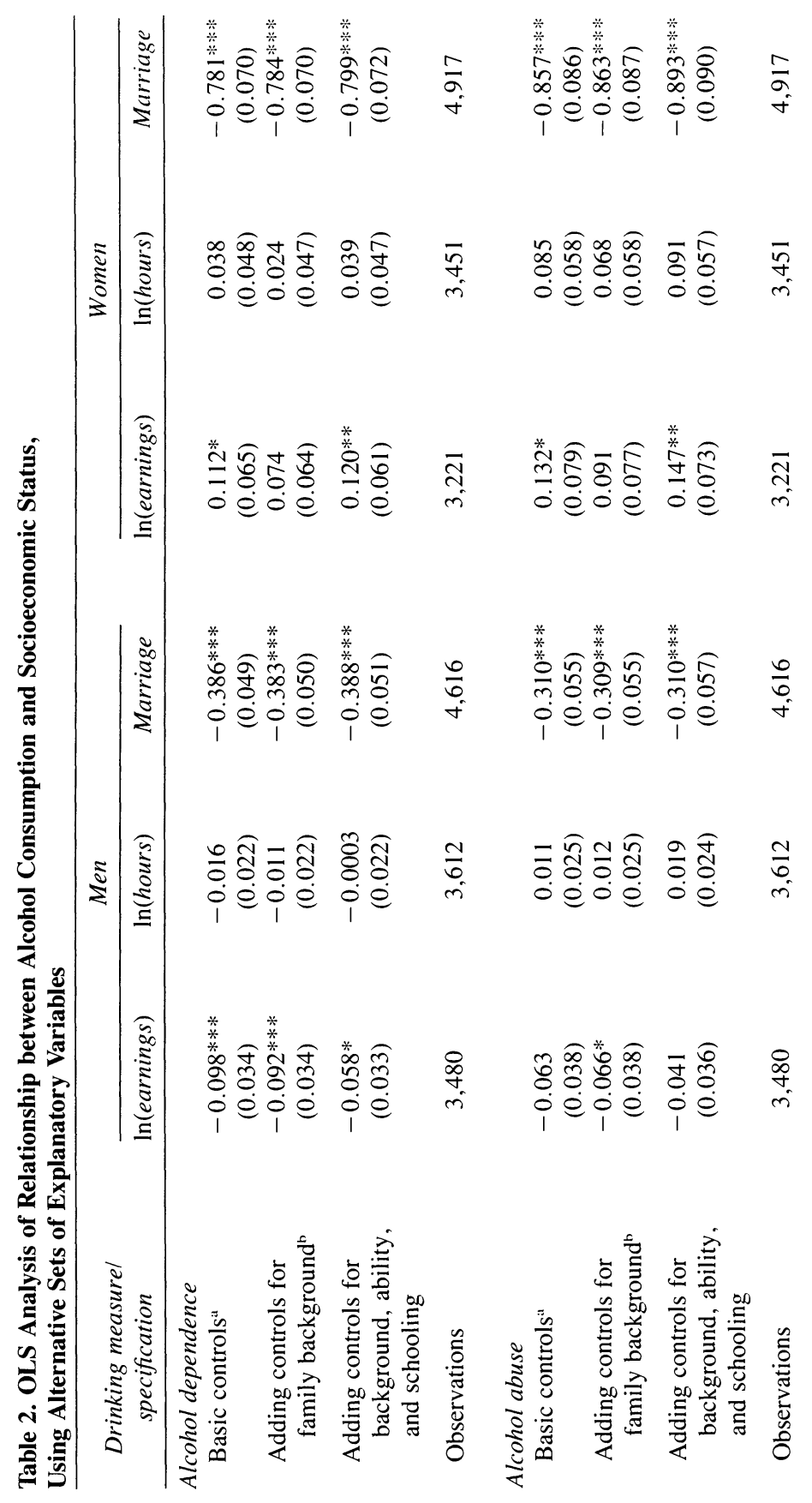




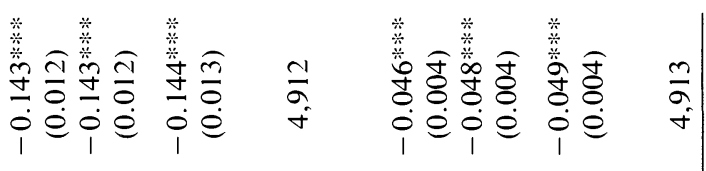

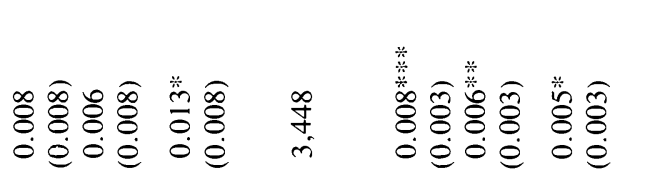

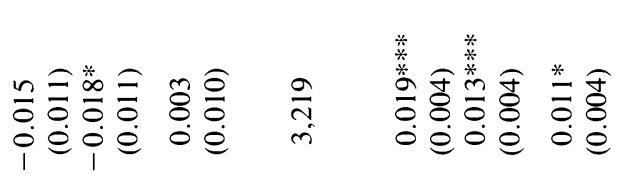

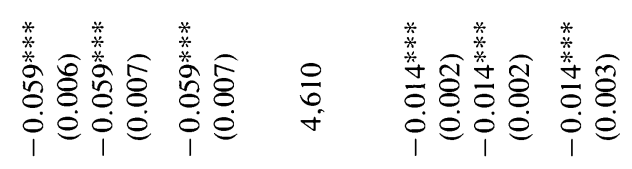

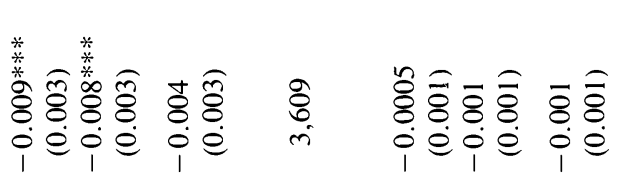

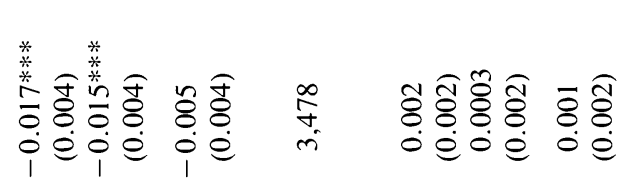

章 
the positive effects for women increase. Surprisingly, controls for background and ability have almost no effect on the estimated effects of drinking on marriage.

\section{Gender Differences: Additional Results}

There are several reasons why estimates of the socioeconomic effects of alcohol consumption might differ across men and women. An important explanation is that there are gender differences in drinking behavior that are not captured by our measures of general and problem consumption. From appendix A it is clear that women in our sample drink less frequently than men. (Women report fewer than half the number of days drinking reported by men.) On the days on which they do drink, women appear to drink more moderately than men. (Twentytwo percent of women's drinking days and 31 percent of men's drinking days involve instances of heavy consumption.) Alcohol abuse and dependence are also less common among women.

While these descriptive statistics provide evidence of substantial behavioral variation, they may not tell the entire story. For example, the heavy drinking measure has been dichotomized at six drinks per occasion and does not describe whether even heavier drinking occurred. The measures of alcohol abuse and dependence have been similarly dichotomized. Where it has been possible to examine the variables in detail, we have found that women are much more likely than men to be at or near the definitional margins. ${ }^{40}$ Unmeasured variation in the severity of problem behavior may account for much of the difference in estimated effects between men and women. Indeed, in table 2 and throughout most of our empirical analysis, the variable with the most definitional consistency across gender (heavy drinking) yields the most similar results. ${ }^{41}$

40. Among the individuals in our sample for whom dependence or abuse was diagnosed, men reported more instances of symptomatic behavior as well as more instances of destructive behavior (for example, drunk driving or hurting themselves or others) than did women.

41. More subtle differences may reinforce the behavioral distinctions drawn above. Alcohol researchers have found it useful to make a distinction between Type 1 and Type 2 alcoholism; see Cloninger (1987) for a thorough description. Women predominantly develop Type 1 alcoholism, which is associated with late onset (usually after age twentyfive) and is found among individuals who are anxious, inhibited, and likely to feel guilt over their dependence. Type 2 alcoholism, which typically involves early onset, a high 
Table 3 lists results from models that incorporate measures of both general consumption and problem drinking as well as all of the background, ability, and basic controls used in our previous specifications. The resulting estimates are useful in distinguishing the effects of moderate and excessive consumption. By providing a more complete description of consumption patterns, the combined measures also reduce some of the unmeasured behavioral variation across gender. Not surprisingly, the results for men and women move closer together. For men the earnings effects of dependence, abuse, and heavy drinking become more negative when general consumption is added, while the effects of general consumption become slightly more positive. The positive effects associated with dependence, abuse, and general consumption for women are smaller than the corresponding estimates from table 2. The earnings effects of heavy and general consumption for women both increase in magnitude. Interestingly, the estimated net effect of heavy drinking is almost the same for men's and women's earnings. Similar to the earnings results, the effects of alcohol consumption on marriage move closer together when combined measures are used. As in table 2 the labor supply effects for both sexes are generally insignificant.

Beyond the differences in drinking behavior, there may be other important differences in the determinants of socioeconomic status that are sex specific. For example, men are more likely than women to work outside the home. Selectivity related to the labor force participation decision may explain some of the gender difference in earnings and hours effects; this will be especially true if alcohol consumption has strong effects on individuals with marginal work attachment. To test for these effects, we estimated selectivity-corrected versions of each of the specifications listed in tables 2 and 3 . No evidence of selectivity bias was found for the earnings equations. Selectivity was present in the hours regressions; however, there was little difference in the corrected and uncorrected alcohol coefficient estimates. As a consequence,

degree of risk taking, and violent and antisocial behavior, is more characteristic of problem drinking by men. Given these differences, especially the persistence and early onset associated with Type 2 behavior, it is not unreasonable that we might observe more drinking-related complications among the young men in our sample. Moreover, to the extent that environmental factors are more likely to influence Type 1 alcoholism, we should expect simultaneity bias to be a more severe problem among women. 


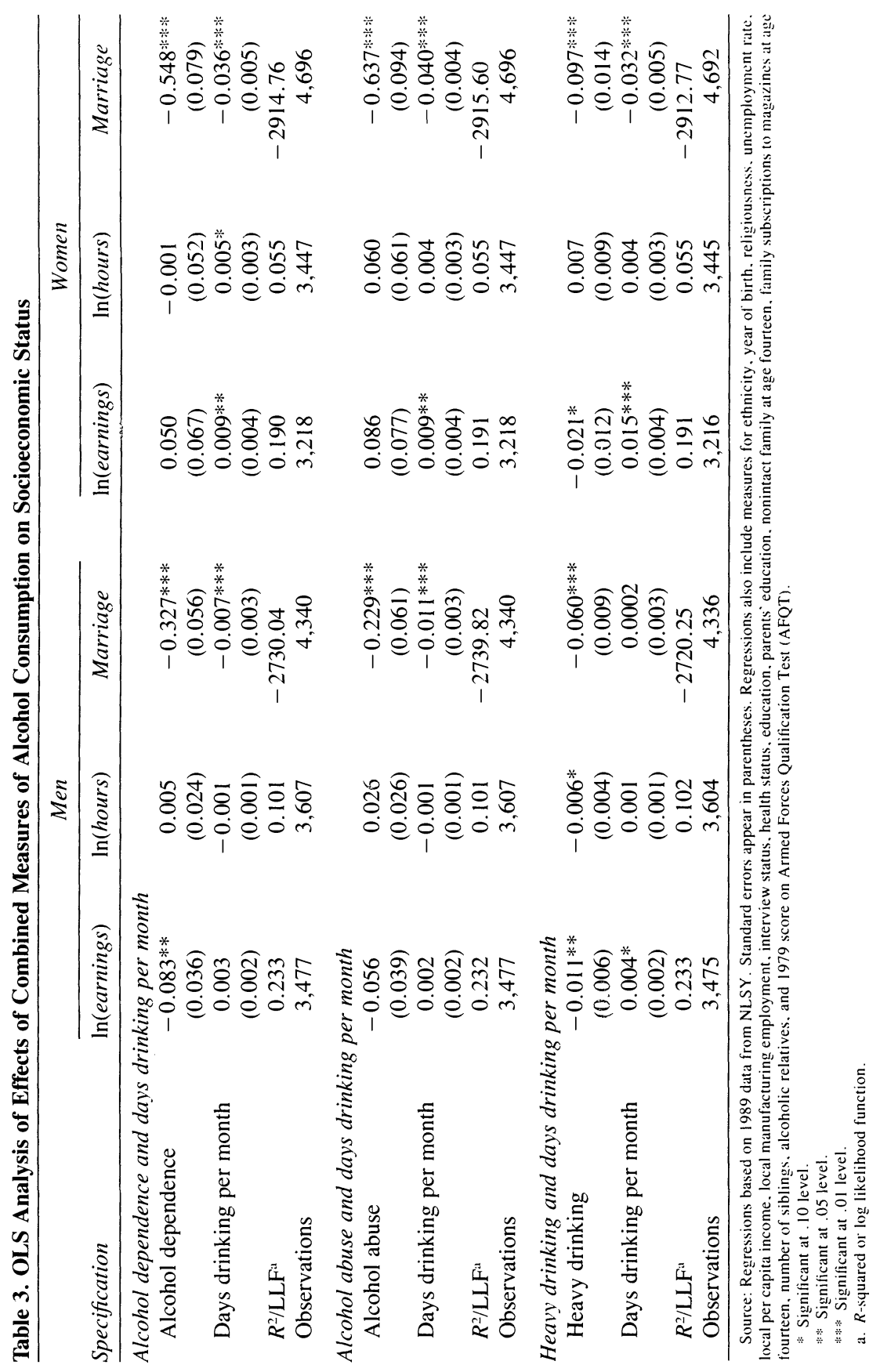


we report only the uncorrected estimates. As part of the selectivity corrections, we also estimated (but did not report) probit models of the labor force participation decision. The estimated effects of the alcohol measures on labor force participation are qualitatively similar to the estimated effects on hours worked conditional on participation.

Factors associated with household structure may also account for some of the differences in the market effects of alcohol across gender. In particular, the labor market effects of marriage and children vary greatly across men and women. While marriage and children are associated with positive labor supply and earnings outcomes for men, they appear to have substantial negative effects for women. ${ }^{42}$ If we assume that household structure is exogenous to the earnings and hours decisions but endogenous to alcohol consumption, then marital status and the presence of children may represent an important source of omitted variables bias in our regressions. To examine the effects that these variables might have, we added marriage and children to the other controls from table 2 . The results from table 4 indicate that when controls for household structure are included, there is no statistical difference across gender in the economic effects of alcohol consumption.

\section{Comparisons of Siblings}

While the results in tables 3 and 4 are helpful in reconciling differences between men and women in our sample, they do not fully address other econometric issues. To examine the problem of omitted personal attributes more carefully, we make use of siblings comparisons in the next set of results. An analysis of variance reveals that family effects account for 50 to 60 percent of the total observed variation in the socioeconomic outcomes and alcohol measures, suggesting that siblings comparisons are a potentially valuable approach to reducing unobserved heterogeneity.

Table 5 uses an estimator that is based on simple differences across same-sex siblings to eliminate family-specific fixed effects. While the specification is similar to those used previously, estimation of family fixed-effects models requires a few modifications. The models include

42. Korenman and Neumark $(1991,1992)$ are good examples of recent empirical research in this area. 
Table 4. OLS Analysis of Relationship between Alcohol Consumption and Socioeconomic Status, Controlling for Marriage and Children

\begin{tabular}{lccccc}
\hline & \multicolumn{2}{c}{ Men } & & \multicolumn{2}{c}{ Women } \\
\cline { 2 - 3 } \cline { 5 - 6 } Specification & $\ln ($ earnings $)$ & $\ln ($ hours $)$ & & $\ln ($ earnings $)$ & $\ln ($ hours $)$ \\
\hline Alcohol dependence & -0.002 & 0.025 & & 0.026 & -0.050 \\
& $(0.032)$ & $(0.022)$ & & $(0.060)$ & $(0.046)$ \\
$R^{2}$ & 0.276 & 0.122 & & 0.238 & 0.117 \\
Observations & 3,480 & 3,612 & & 3,221 & 3,451 \\
Alcohol abuse & 0.005 & 0.040 & & 0.059 & 0.009 \\
& $(0.035)$ & $(0.024)$ & & $(0.072)$ & $(0.056)$ \\
$R^{2}$ & 0.276 & 0.122 & & 0.238 & 0.117 \\
Observations & 3,480 & 3,612 & & 3,221 & 3,451 \\
Heavy drinking & 0.004 & -0.001 & & -0.011 & 0.0001 \\
& $(0.004)$ & $(0.003)$ & & $(0.010)$ & $(0.008)$ \\
$R^{2}$ & 0.277 & 0.122 & & 0.238 & 0.117 \\
Observations & 3,478 & 3,609 & & 3,219 & 3,448 \\
Days drinking per month & $0.003 *$ & 0.0004 & & 0.003 & -0.001 \\
$R^{2}$ & $(0.002)$ & $(0.001)$ & & $(0.003)$ & $(0.003)$ \\
Observations & 0.277 & 0.122 & & 0.238 & 0.117 \\
\cline { 6 - 6 } & 3,477 & 3,607 & 3,218 & 3,447 \\
\hline
\end{tabular}

Source: Regressions based on 1989 data from NLSY. Standard errors appear in parentheses. Regressions also include measures for ethnicity, year of birth, religiousness. unemployment rate, local per capita income, local manufacturing employment, interview status, health status, education, parents' education, nonintact family at age fourteen, family subscriptions to magazines at age fourteen, number of siblings, alcoholic relatives, and 1979 AFQT score, marital status, and children.

* Significant at . 10 level.

almost the same set of explanatory control variables used in the models in tables 2 and 3, but measures that show no variation across siblings (for example, ethnicity, alcoholic relatives, and so on) cannot be included. Another modification required is the use of conditional logit (instead of probit) to estimate the determinants of marital status. Maximum likelihood estimation of fixed-effects probit models yields inconsistent parameter estimates. ${ }^{43}$

The estimates from table 5 essentially confirm our earlier models that used the full set of controls for family background and personal attributes. In principle, comparisons of siblings have important advantages, but in this application the alternative approaches of using either explicit measures or family fixed effects to reduce omitted variables

43. See Maddala (1987) for a review of fixed-effects models with qualitative dependent variables. 
bias appear to work equally well. At least in part this is due to the detailed measures available in the NLSY ${ }^{44}$ Taken together, the results of the alternative approaches indicate that at least part of the negative relationship between drinking and men's earnings reported in previous studies is attributable to unobserved differences in family background.

Compared with the table 2 results, the results from the siblings model suggest an even larger positive effect of alcohol problems on women's earnings and hours. The point estimates imply that a diagnosis of alcohol dependence increases a woman's earnings by 49 percent and increases hours worked by 36 percent; the point estimates for alcohol abuse likewise imply large positive effects. Although there are plausibly productive effects of moderate drinking, there is no indication in table 5 that this is the correct interpretation of the results. When entered by itself, the measure of days drinking in the past month is not associated with women's earnings. When the days drinking measure is entered in combination with the problem drinking measures, the coefficient estimates on the problem drinking measures remain positive. Given the lack of a plausible explanation for the positive results, the estimates from table 5 suggest that simultaneity bias may be a substantial problem.

The siblings results still show a strong negative effect of alcohol consumption on the probability of marriage. Again using calculated marginal effects to illustrate the magnitude, we can see that alcohol dependence and abuse reduce the likelihood of men's marriage by 17 and 13 percent respectively, very close to the marginal effects implied by table $2 .{ }^{45} \mathrm{As}$ in table 2 the negative effects of drinking on the likelihood of marriage for women are two to three times larger than for men. The similarities between the results reported in tables 2 and 5 provide more evidence that omitted variables bias is not a significant problem in the marriage results.

44. This contrasts with the results of Geronimus and Korenman (1992); they found that siblings models yielded importantly different estimates of the socioeconomic consequences of teen childbearing.

45. The coefficients for the marriage models in table 5 cannot be directly compared with the coefficients in table 2 because of the difference between probit and logit. For the logit models reported in table 5, the marginal effect of alcohol on marriage can be calculated as $\exp (\hat{m}) /[1+\exp (\hat{m})]^{2} \beta$, where $\beta$ is the logit coefficient on drinking. 


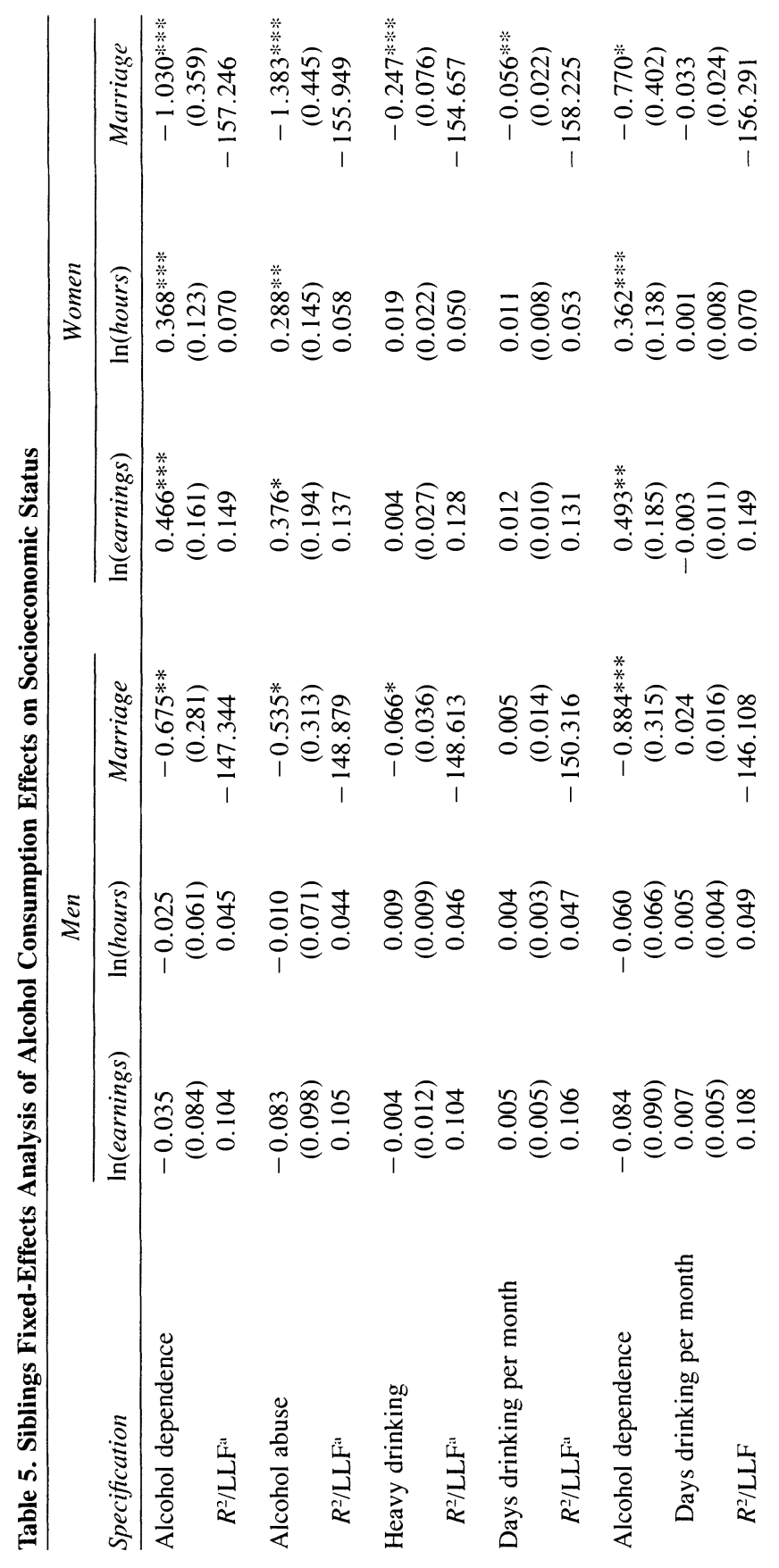




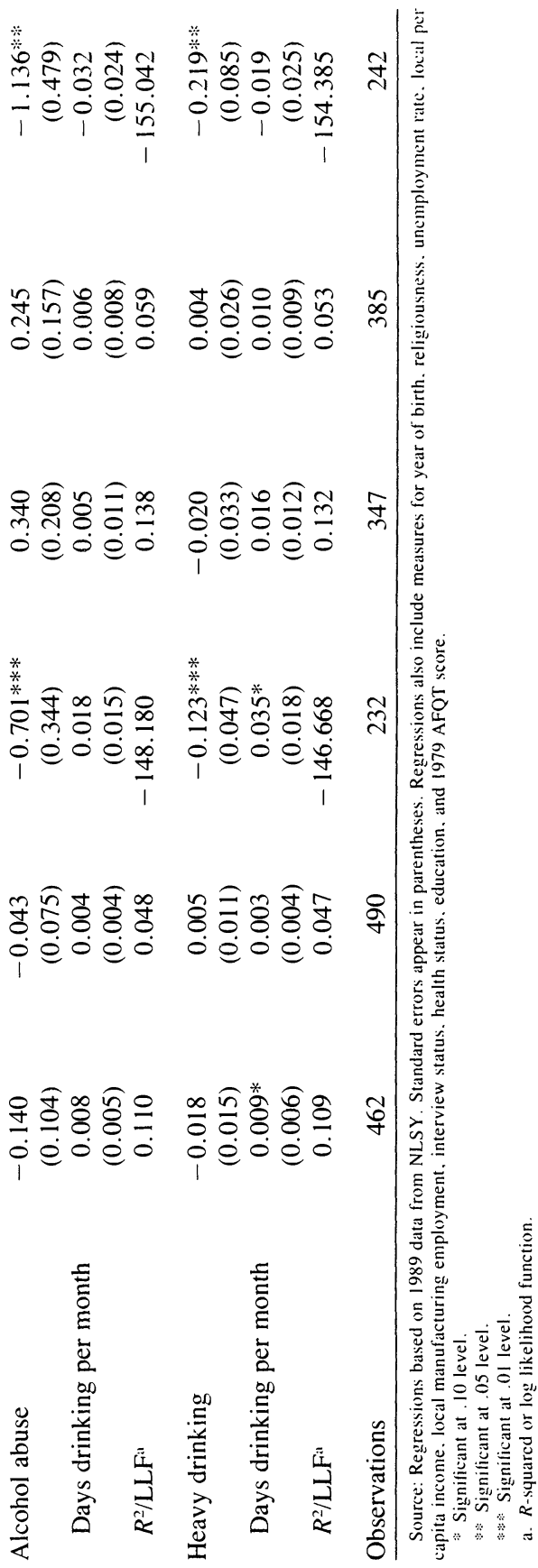




\section{Longitudinal Models}

Table 6 reports the results of longitudinal fixed-effects analyses, using both one-year and four-year differences ${ }^{46}$ An analysis of variance suggests that longitudinal controls, which explain from 55 to 70 percent of the total observed variation in the socioeconomic outcome and alcohol measures, also hold some promise in reducing unobserved heterogeneity. Because of data limitations in the NLSY, these models can only be estimated using the measures of heavy drinking and days drinking per month. Estimation of longitudinal fixed-effects models requires a few modifications similar to the modifications necessary for estimation of the siblings models: time invariant variables (ethnicity, date of birth, and so on) are not available, and conditional logit is used for the marriage models.

In the longitudinal results, positive earnings effects are found for both men and women. While the benchmark results from table 2 imply that each occurrence of heavy drinking reduces earnings by 1.7 percent for men and 1.5 percent for women, the longitudinal fixed-effects results imply that each occurrence of heavy drinking increases earnings by 1.3 percent for men and 1.5 percent for women. Again, the results do not seem to be explained by a positive effect of moderate drinking, since a positive effect of heavy drinking remains when both measures of alcohol consumption are used. The one-year and four-year differences show approximately the same picture.

It is useful to carefully compare the results reported in table 6 with the results from the OLS models and siblings comparisons. Consider the estimated effects of alcohol consumption on men's earnings. Starting with benchmark results showing substantial negative effects, the earlier approaches of using explicit controls and family fixed effects yielded estimates which, while still negative, were much closer to zero. In contrast, using individual fixed effects yields positive and statistically significant estimates. This suggests two plausible (and not mutually exclusive) interpretations. First, as a more complete control for individual heterogeneity, the longitudinal fixed-effects models effectively eliminate omitted variables bias but uncover a large positive bias from contemporaneous budget constraint simultaneity. Alternatively,

46. Results similar to those reported in table 5 obtain when we use mean difference and random-growth longitudinal fixed-effects estimators. Results available upon request. 
the longitudinal models may simply exacerbate a small positive existing simultaneity bias.

Once again, the patterns of results for women's earnings, hours, and marital status provide additional clues. The individual fixed-effects estimates show smaller positive impacts of alcohol consumption on women's earnings and hours than did the previous methods. This is not entirely consistent with the interpretation that the men's results indicate the existence of a large positive simultaneity bias. Instead, a small simultaneity bias may exist, or there may also be measurement error problems creating a bias toward zero. The marriage results continue to be somewhat different and show that alcohol consumption is still associated with a lower probability of being married. This is entirely consistent with the earlier interpretation that individual heterogeneity was not an important source of bias in the marriage models.

\section{Instrumental Variables Models}

Table 7 reports results from the last approach used, instrumental variables analysis. In theory, this approach provides a solution to the problems of omitted variables, simultaneity, and measurement error. Practical issues arise, however, in finding instruments that are sufficiently strong predictors of alcohol consumption but convincingly not directly related to socioeconomic status. For the models reported in table 7, the percentage of the state's population residing in dry counties, the average beer price, parents' alcoholism, and other distant relatives' alcoholism are used as identifying variables. ${ }^{47}$ Table 7 reports the coefficient estimates for the IV models estimated, as well as test statistics for model fit and exogeneity. Particularly for the earnings models, exogeneity of the alcohol measures is usually rejected, providing support for the specification.

The IV results reported in table 7 provide the strongest indication that alcohol problems have important socioeconomic consequences. A number of features of the results are notable. First, in sharp contrast to the benchmark OLS results, the results are much more similar for men and women. In particular, the point estimates of the effects of alcohol

47. The results of alternative specifications using all of the above IVs except parents' alcoholism are similar to the results reported in table 7 . These results are available upon request. 


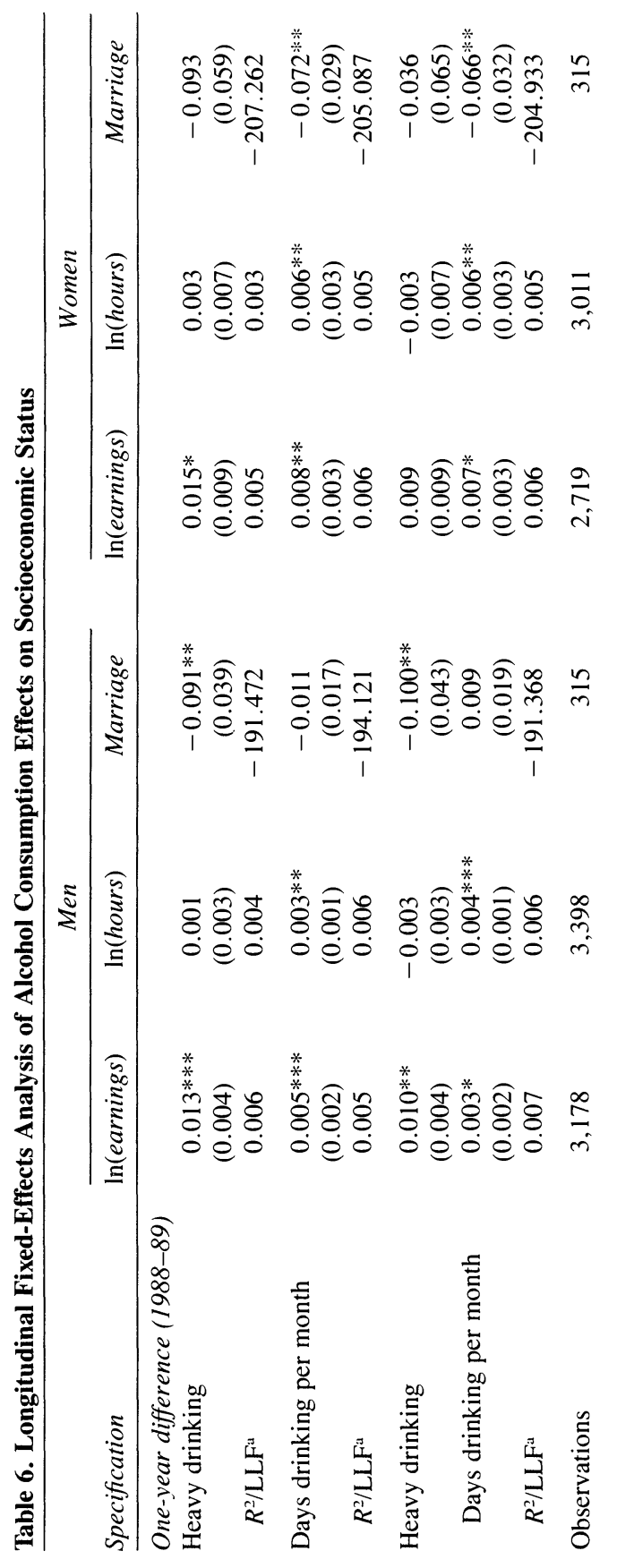




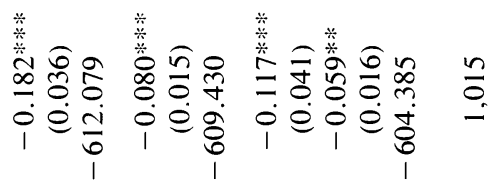

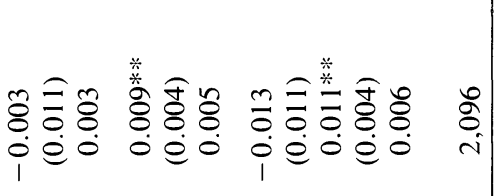

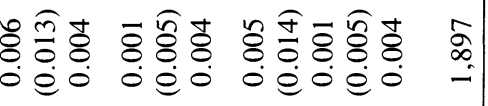

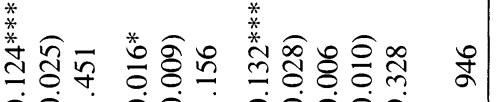

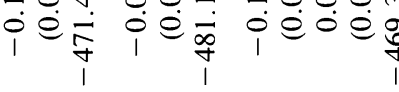

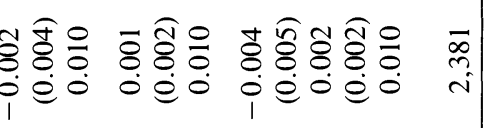

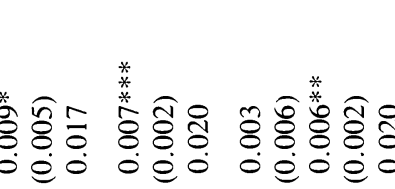

茨

กิ

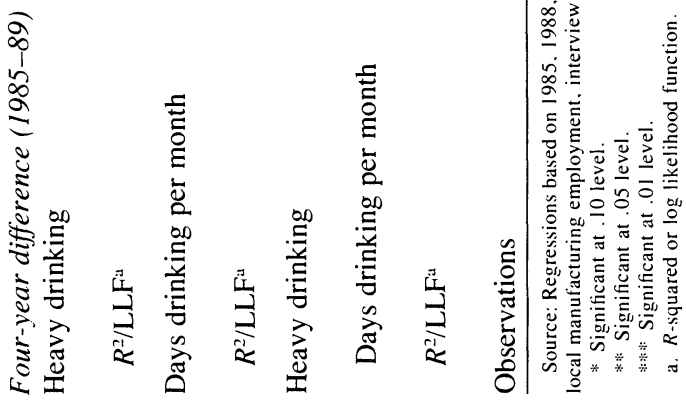




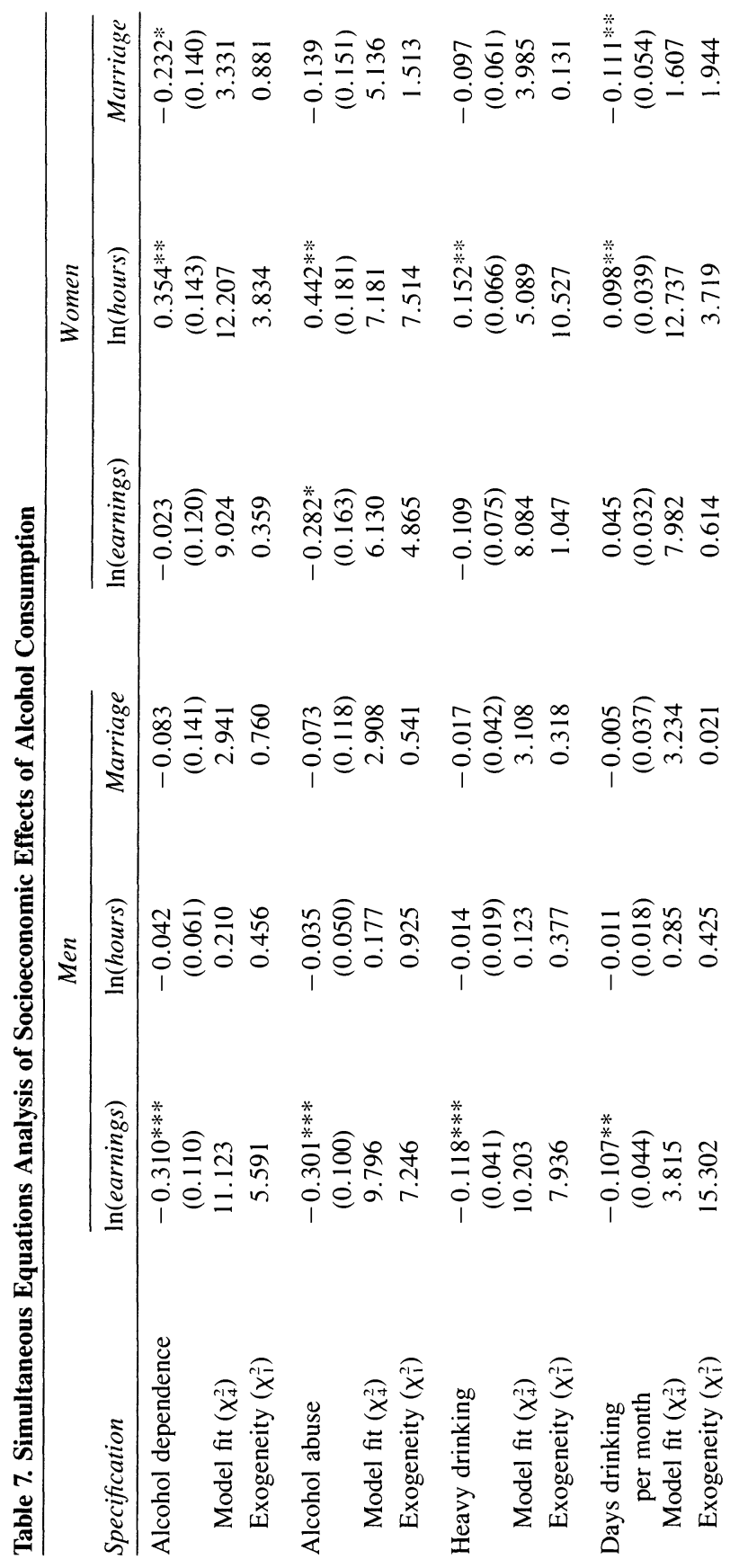




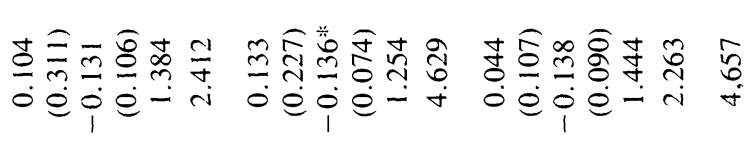

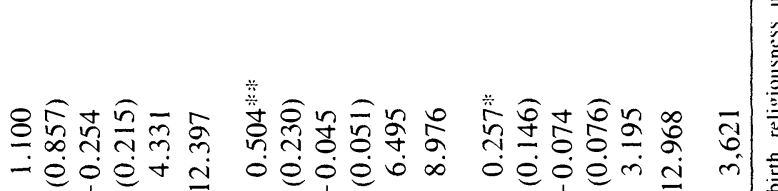

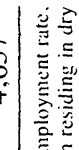
i.jo边

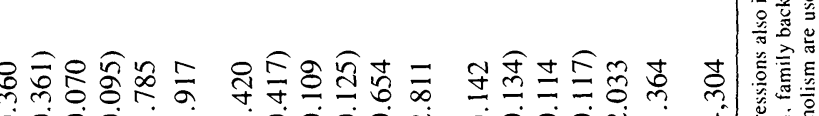
jeoj-i

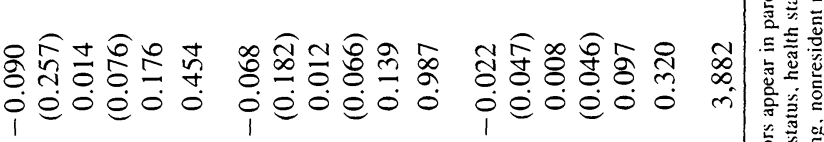

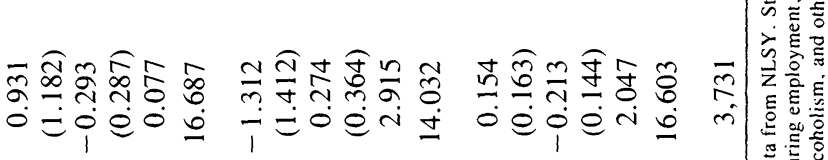

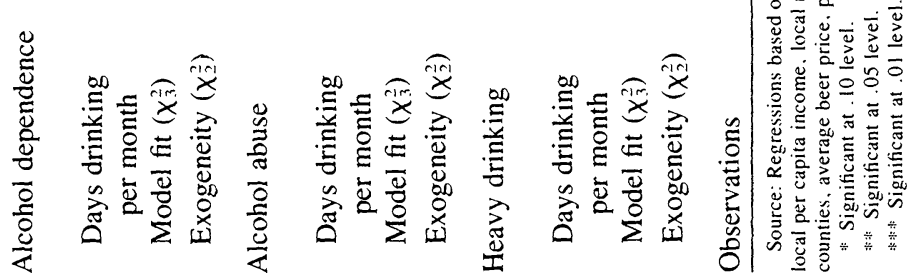


abuse or heavy drinking on men's and women's earnings are virtually identical and suggest that alcohol problems cause about a 30 percent drop in earnings. The results for the other alcohol measures are not quite as similar. One anomalous pattern remains: while there is little effect of alcohol problems on men's hours, women with alcohol problems appear to work more hours.

Second, the IV models produce estimates of earnings effects that are more consistently negative across alcohol measures; the estimates are uniformly negative for men. There is no longer any significant evidence of positive productivity effects of moderate drinking. When entered alone, the number of days of drinking in the past month has nearly the same negative effect on earnings as does the number of days of heavy drinking in the men's equation. When entered in combination, the results do not provide any indications of positive effects.

Third, the relationship between alcohol consumption and marital status is usually negative. However, the coefficient estimates are mostly smaller in magnitude and less precisely estimated than were our previous results. The smaller point estimates are consistent with our hypothesis of reverse causality and a consequently reinforcing negative bias in the benchmark estimates of the effects of drinking on marital status. However, exogeneity of the alcohol measures is formally rejected in only a handful of the marriage models.

\section{Policy}

Although estimates of negative effects of alcohol problems on earnings have attracted policy attention, estimates indicating no effect, or even a positive effect, have appeared in the literature. In this paper we replicate and provide some methodological explanation for this range of results. On balance, we believe our results provide new evidence that alcohol problems have a direct negative impact on earnings, although this impact may be small. The negative effect of alcohol on the probability of marriage appears to be a more robust empirical finding. While we believe our systematic investigation provides a foundation for future consensus, it is clear that a consensus has yet to be forged. How does evidence that problem drinkers might suffer adverse socioeconomic consequences provide guidance for policy? 
To begin to answer this question, it is useful to consider how estimates of the socioeconomic consequences of alcohol consumption can play a role in the policy process. In the past the estimates often were used as a rhetorical device to advance the argument that alcohol abuse is a serious policy problem comparable to other health problems such as cancer, heart disease, or AIDS. This use has led to the general criticism that estimates of the total productivity losses due to alcohol problems are not relevant for decisions about policies that will change the consumption of alcohol at the margin. ${ }^{48}$ This criticism in turn points to a more useful role for the earnings loss estimates, as an input when evaluating the effects of specific policy changes (for example, the new warning labels on alcoholic beverages, advertising bans, new alcohol taxes, and so on). In fact, our analysis yielded additional results useful for further steps in alcohol policy analysis. In the simultaneous equations models we estimated reduced-form equations showing alcohol demand as a function of various exogenous influences, including alcohol prices. The estimated price coefficients from the reduced-form demand equations (not reported) can be expressed as elasticities, taking account of the qualitative and limited nature of the alcohol measures. ${ }^{49}$ The results imply that the price-elasticity of the probability of being alcohol dependent is -0.45 for men and -0.41 for women. The corresponding price-elasticities for the probability of abuse are -1.2 and -1.6 . The price-elasticity of the demand for heavy drinking is -0.58 for men and -0.42 for women. The only anomalous result is a positive price-elasticity for the number of days of drinking for women (0.29), although it is negative for men $(-0.24)$. These estimates compare well to previous estimates in the literature; in particular, they support previous findings that even heavy drinking responds to price. ${ }^{50}$ Combined with our estimates of earnings losses, these elasticity estimates imply that increasing alcohol taxes could lead to increased productivity and earnings.

Economists have argued that even in the context of specific policies,

48. This point does not apply to the analysis by Fisher (1926), since he was explicitly considering a policy, Prohibition, which if effective would eliminate all alcohol problems. However, in practice even Prohibition did not eliminate alcohol problems; see Miron and Zweibel (1991).

49. See Maddala (1983).

50. Kenkel (1993) reviews estimates of price-elasticities for young adults in this range. 
estimates of the lost earnings associated with alcohol abuse offer insufficient and possibly misleading guidance. The fundamental conceptual problem is that the estimates fail to distinguish between costs to the individual and costs the individual imposes on society (externalities). The worker is the primary loser when his or her earnings are reduced by alcohol consumption. ${ }^{51}$ Using the standard of consumer sovereignty, even if estimates imply that increasing alcohol taxes can lead to increased earnings, it does not follow that the tax policy is justified. However, if alcohol problems are beyond the control of the individual, it may make sense to view the entire earnings losses as relevant numbers to evaluate policy. ${ }^{52}$ The earnings loss estimates also gain policy relevance to the extent that people are poorly informed about the productivity effects of their drinking, in the same way they appear to be poorly informed about the health, safety, and legal consequences. ${ }^{53}$

Assuming that policymakers have decided that the socioeconomic consequences of alcohol consumption are of some relevance at a conceptual level, the practical problem remains: which set of empirical estimates, if any, is correct? The lack of consensus on the correct answer suggests caution in basing policy on the evidence we have now. As future studies try to remedy this situation, researchers, and the policy community as eventual users of that research, need to identify the most important empirical problems encountered in estimating the effects of alcohol problems on socioeconomic status. Our results suggest that omission of family background and personality measures creates some bias toward finding a negative relationship between earnings and alcohol consumption. In our data family effects and individual effects capture a significant amount of the observed variation in earnings and

51. See Manning and others (1991) for an in-depth discussion of the distinction between the internal and external costs of heavy drinking, smoking, and sedentary lifestyles. Heien and Pittman (1993) concluded that earnings losses and other internal costs account for most (six-sevenths) of the total economic costs of alcohol abuse estimated by Rice and others (1990).

52. In a similar vein Pogue and Sgontz (1989) argued that the optimal tax rate on alcohol is much higher, perhaps as high as 306 percent of the net of tax price, if alcoholism is considered a disease beyond the control of the individual.

53. Kenkel (1991b) provided evidence that many consumers are unaware of at least some of the health consequences of heavy drinking. Phelps (1987) found suggestive evidence that young adults underestimate the safety risks of driving after drinking. Snortum, Berger, and Hauge (1989) found that many Americans are unaware of various legal aspects of drinking and driving. 
alcohol consumption, demonstrating the potential usefulness of siblings and longitudinal data. ${ }^{54}$ However, the more important empirical problem appears to be contemporaneous simultaneity, where higher earnings lead to more drinking. The ideal approach to this problem is a structural dynamic model of alcohol and labor market decisions.

As more sophisticated econometric approaches are developed, researchers should not lose sight of the inherent difficulties in measurement. The researcher needs to make the sometimes subtle distinction between problem drinking and other alcohol consumption. Moreover, problem drinking is not a simple phenomenon. Research could usefully address whether the different patterns of behavior that fall under the general label of problem drinking have different impacts on socioeconomic outcomes. This is a particularly promising approach to understanding gender differences, since the "typical" male alcoholic appears to be different from the "typical" female alcoholic. ${ }^{55}$ The effects of problem drinking on socioeconomic outcomes may also be quite subtle. To shed more light it is probably necessary to go beyond measures of wages and hours worked and examine other aspects of work performance, including both short-run outcomes (such as absenteeism, tardiness, and on-the-job accidents) and long-run outcomes (such as occupational choices and retirement).

\section{Conclusion}

Our in-depth empirical analysis yielded many estimates of the effects of alcohol on socioeconomic outcomes. We offer the following interpretation of the pattern of results. The benchmark OLS estimates of the effects of alcohol problems on socioeconomic outcomes may reflect two sources of bias working in opposite directions. Because of omitted variables bias, the negative effects of alcohol problems are overstated in models that imperfectly control for deficiencies in childhood environment and personality disorders. As alternative strategies are used to control for the individual and family heterogeneity-including a richer set of controls, siblings comparisons, and longitudinal fixed-effects

54. A promising data source is the Longitudinal Alcohol Epidemiologic Survey by the U.S. Department of Commerce, Bureau of the Census.

55. See footnote 41 above for a description of different types of alcoholism. 
models - another source of bias is uncovered and possibly exacerbated. Contemporaneous simultaneity (for example, from the income effect of earnings on drinking problems) creates a positive bias. Once simultaneity is addressed using instrumental variables estimators, alcohol problems are estimated to lead to significantly reduced earnings.

Our instrumental variables estimates suggest that the negative impact of alcohol problems on earnings is somewhat larger than both our benchmark OLS estimates and many estimates from previous research suggest. While we find little evidence that alcohol problems have a negative impact on labor supply, there also appears to be a negative effect of problem drinking on marriage. As we argued in the last section, this type of evidence provides limited but useful guidance for the design of alcohol policies. It should be noted that the results in this paper apply to a sample of young adults, none of whom is older than thirty-one. Some other research suggests that older adults may suffer larger earnings losses as the cumulative health effects of chronic abuse become apparent. ${ }^{56}$ At the same time, the possible beneficial health effects of moderate alcohol use may also only become apparent for older adults. Moderate alcohol use appears to protect against heart disease, an effect that is unlikely to be relevant for people in the age group of the NLSY sample. Analysis of new data is needed to determine if alcohol abuse is more harmful or alcohol use is more helpful for older adults.

56. Mullahy and Sindelar (1993) and Rice and others (1990) find much larger losses for individuals aged thirty to sixty than for young adults. 


\section{Appendix}

Table A-1. National Longitudinal Survey of Youth (NLSY) Variable Means: Full Sample, Siblings Sample, and Longitudinal Sample

\begin{tabular}{llllll}
\hline & \multicolumn{2}{c}{ Men } & & \multicolumn{2}{c}{ Women } \\
\cline { 2 - 3 } \cline { 5 - 6 } Variable & Mean & $\begin{array}{l}\text { Standard } \\
\text { deviation }\end{array}$ & & Mean & $\begin{array}{l}\text { Standard } \\
\text { deviation }\end{array}$ \\
\hline
\end{tabular}

Full sample

1989 Outcomes

Log(earnings divided by $\$ 1,000$ )

$\log$ (hours divided by 100 )

$\begin{array}{llll}9.48 & (0.88) & 8.99 & (1.07) \\ 7.57 & (0.55) & 7.25 & (0.79) \\ 0.46 & (0.50) & 0.54 & (0.50) \\ 0.20 & (0.40) & 0.08 & (0.28) \\ 0.15 & (0.36) & 0.05 & (0.23) \\ 2.01 & (3.09) & 0.63 & (1.75) \\ 6.44 & (7.92) & 2.81 & (4.99)\end{array}$

Marriage

Alcohol dependence

Alcohol abuse

Heavy drinking

Days drinking per month

(7.92)

Personal characteristics

African origin
Latino origin
Year of birth
Religious
Interview status
Health status
Completed high school
Completed college
AFQT score
Children

$\begin{array}{rrrr}0.27 & (0.44) & 0.26 & (0.44) \\ 0.16 & (0.37) & 0.16 & (0.37) \\ 60.65 & (2.22) & 60.51 & (2.22) \\ 0.41 & (0.49) & 0.49 & (0.50) \\ 0.12 & (0.32) & 0.06 & (0.24) \\ 0.04 & (0.19) & 0.05 & (0.21) \\ 0.80 & (0.40) & 0.84 & (0.37) \\ 0.16 & (0.37) & 0.17 & (0.37) \\ 183.45 & (39.87) & 184.44 & (36.38) \\ 1.04 & (1.18) & 1.47 & (1.29)\end{array}$

Family background

Mother's education

9.99

$(4.17)$

10.17

(3.84)

Mother's education missing

0.07

$(0.26)$

0.05

$(0.22)$

Father's education

9.25

$(5.29)$

9.19

(5.23)

Father's education missing

0.15

$(0.35)$

0.15

$(0.35)$

Nonintact family at age fourteen

0.32

$(0.47)$

0.33

$(0.47)$

Siblings

3.88

(2.65)

3.96

(2.68)

Magazines at age fourteen

Alcoholic mother/stepmother

0.55

$(0.50)$

0.54

$(0.50)$

Alcoholic father/stepfather

0.04

$(0.19)$

0.05

$(0.23)$

0.18

$(0.38)$

0.23

$(0.42)$

Other alcoholic relative

0.23

(0.42)

0.25

(0.44)

Local variables

Unemployment rate

5.50

(1.94)

5.55

Per capita income (divided by $\$ 10,000$ )

1.31

(3.82)

1.37

(1.98)

Manufacturing employment

0.15

$(0.08)$

0.15

(3.95)

Adjusted beer price

2.59

$(0.26)$

2.59

$(0.08)$

Percentage of state population residing in dry counties

$1.89 \quad(5.82) \quad 2.24$

(0.26)

(6.56) 
Table A-1. National Longitudinal Survey of Youth (NLSY) Variable Means: Full Sample, Siblings Sample, and Longitudinal Sample (Continued)

\begin{tabular}{llllll}
\hline & & \multicolumn{2}{c}{ Men } & & \multicolumn{2}{c}{ Women } \\
\cline { 2 - 5 } \cline { 5 - 6 } Variable & Mean & $\begin{array}{l}\text { Standard } \\
\text { deviation }\end{array}$ & & Mean & $\begin{array}{l}\text { Standard } \\
\text { deviation }\end{array}$ \\
\hline
\end{tabular}

\section{Siblings sample}

1989 Outcomes

$\begin{array}{lllll}\text { Log }(\text { earnings divided by } \$ 1,000) & 9.41 & (0.91) & 9.04 & (1.00) \\ \text { Log(hours divided by 100) } & 7.55 & (0.56) & 7.25 & (0.81) \\ \text { Marriage } & 0.44 & (0.50) & 0.51 & (0.50) \\ \text { Alcohol dependence } & 0.20 & (0.40) & 0.08 & (0.28) \\ \text { Alcohol abuse } & 0.15 & (0.36) & 0.06 & (0.23) \\ \text { Heavy drinking } & 1.90 & (2.95) & 0.64 & (1.75) \\ \text { Days drinking per month } & 6.14 & (7.65) & 2.83 & (5.10)\end{array}$

Personal characteristics

$\begin{array}{lrrrr}\text { African origin } & 0.30 & (0.46) & 0.30 & (0.46) \\ \text { Latino origin } & 0.18 & (0.38) & 0.15 & (0.36) \\ \text { Year of birth } & 60.99 & (2.06) & 61.03 & (1.99) \\ \text { Religious } & 0.43 & (0.50) & 0.53 & (0.50) \\ \text { Interview status } & 0.12 & (0.33) & 0.06 & (0.24) \\ \text { Health status } & 0.04 & (0.19) & 0.04 & (0.20) \\ \text { Completed high school } & 0.78 & (0.42) & 0.85 & (0.35) \\ \text { Completed college } & 0.14 & (0.35) & 0.17 & (0.37) \\ \text { AFQT score } & 176.69 & (38.27) & 181.88 & (36.37) \\ \text { Children } & 0.95 & (1.10) & 1.43 & (1.25)\end{array}$

Family background

Mother's education

$9.78 \quad(4.26) \quad 10.24 \quad(3.73)$

Mother's education missing

0.08

$(0.27)$

0.04

$(0.20)$

Father's education

8.79

$(5.33)$

9.22

(5.19)

Father's education missing

0.16

$(0.37)$

0.13

$(0.34)$

Nonintact family at age fourteen

0.31

$(0.46)$

0.30

$(0.46)$

Siblings

4.48

(2.56)

4.59

(2.73)

Magazines at age fourteen

0.51

$(0.50)$

0.52

$(0.50)$

Alcoholic mother/stepmother

0.03

$(0.17)$

0.04

$(0.21)$

Alcoholic father/stepfather

0.17

$(0.37)$

0.23

$(0.42)$

Other alcoholic relative

0.24

$(0.43)$

0.26

$(0.44)$

Local variables

Unemployment rate

Per capita income (divided by $\$ 10,000$ )

5.53

(1.95)

5.52

1.18

(3.60)

1.17

(1.96)

0.16

$(0.09)$

0.15

(3.70)

Manufacturing employment

2.59

$(0.26)$

$(0.08)$

Adjusted beer price

2.10

(6.32)

2.30

(6.65) 
Table A-1. National Longitudinal Survey of Youth (NLSY) Variable Means: Full Sample, Siblings Sample, and Longitudinal Sample (Continued)

\begin{tabular}{|c|c|c|c|c|}
\hline \multirow[b]{2}{*}{ Variable } & \multicolumn{2}{|c|}{ Men } & \multicolumn{2}{|c|}{ Women } \\
\hline & Mean & $\begin{array}{l}\text { Standard } \\
\text { deviation }\end{array}$ & Mean & $\begin{array}{l}\text { Standard } \\
\text { deviation }\end{array}$ \\
\hline \multicolumn{5}{|l|}{ Longitudinal sample } \\
\hline \multicolumn{5}{|l|}{1985 Outcomes } \\
\hline Log(earnings divided by $\$ 1,000)$ & 9.10 & $(1.04)$ & 8.60 & $(1.21)$ \\
\hline Log(hours divided by 100 ) & 7.47 & $(0.65)$ & 7.12 & $(0.89)$ \\
\hline Marriage & 0.32 & $(0.47)$ & 0.45 & $(0.50)$ \\
\hline Heavy drinking & 1.56 & $(2.94)$ & 0.40 & $(1.48)$ \\
\hline Days drinking per month & 6.81 & $(8.03)$ & 3.00 & $(5.13)$ \\
\hline \multicolumn{5}{|l|}{1989 Outcomes } \\
\hline Log(earnings divided by $\$ 1,000)$ & 9.44 & $(0.90)$ & 8.91 & $(1.09)$ \\
\hline $\log ($ hours divided by 100$)$ & 7.55 & $(0.58)$ & 7.21 & $(0.82)$ \\
\hline Marriage & 0.47 & $(0.50)$ & 0.55 & $(0.50)$ \\
\hline Heavy drinking & 2.09 & $(3.16)$ & 0.64 & $(1.78)$ \\
\hline Days drinking per month & 6.48 & $(8.03)$ & 2.72 & $(5.02)$ \\
\hline \multicolumn{5}{|l|}{1985 Personal characteristics } \\
\hline Interview status & 0.10 & $(0.29)$ & 0.06 & $(0.23)$ \\
\hline Health status & 0.03 & $(0.18)$ & 0.05 & $(0.22)$ \\
\hline Children & 0.78 & $(0.97)$ & 1.26 & $(1.13)$ \\
\hline \multicolumn{5}{|l|}{1989 Personal characteristics } \\
\hline Interview status & 0.13 & $(0.33)$ & 0.06 & $(0.24)$ \\
\hline Health status & 0.04 & $(0.19)$ & 0.05 & $(0.21)$ \\
\hline Children & 1.08 & $(1.17)$ & 1.56 & $(1.28)$ \\
\hline \multicolumn{5}{|l|}{1985 Local variables } \\
\hline Unemployment rate & 8.21 & $(3.00)$ & 8.24 & $(3.05)$ \\
\hline Per capita income (divided by $\$ 10,000$ ) & 1.27 & $(3.68)$ & 1.24 & $(3.55)$ \\
\hline Manufacturing employment & 0.16 & $(0.09)$ & 0.16 & $(0.09)$ \\
\hline \multicolumn{5}{|l|}{1989 Local variables } \\
\hline Unemployment rate & 5.53 & $(1.99)$ & 5.57 & $(1.99)$ \\
\hline Per capita income (divided by $\$ 10,000$ ) & 1.47 & $(4.07)$ & 1.55 & $(4.16)$ \\
\hline Manufacturing employment & 0.15 & $(0.09)$ & 0.15 & $(0.08)$ \\
\hline
\end{tabular}

Source: Based on data from the NLSY. 


\section{Comments and Discussion}

Comment by Philip J. Cook: An early effort to estimate the productivity costs of drinking was made by Irving Fisher. "All of us know that industrial efficiency was one of the chief reasons for Prohibition,", he asserted in a book published in 1926.' In support of his belief that drinking slows down the "human machine," he cited an experiment conducted in Germany. Four typesetters were studied over a four-day period; two of them were given drinks, and the other two served as a control group. The experimenter's conclusion was that drinking three glasses of beer in a day reduced productivity by about 10 percent. Fisher made a breathtaking extrapolation from this result, estimating a 5 percent increase in national productivity as a result of Prohibition-induced reduction in drinking.

More recent research has used larger data bases and more sophisticated methods but has not necessarily reached more reliable conclusions. ${ }^{2}$ The evidence utilized by Fisher was derived from an experiment and had a straightforward interpretation. Modern research in this area, in contrast, has attempted the conceptually more difficult task of estimating causal effects from nonexperimental data. In their paper, Kenkel and Ribar confront this challenge with an exceptionally rich dataset (the National Longitudinal Survey of Youth, or NLSY) and an arsenal of econometric methods. Together with the recent paper of Mullahy and Sindelar, ${ }^{3}$ Kenkel and Ribar now define the state of the art for this sort of research. Yet we are left with considerable uncertainty about whether

1. Fisher (1926, p. 158).

2. Cook (1991).

3. Mullahy and Sindelar (1993). 
a successful national policy to reduce alcohol abuse (not necessarily prohibition!) would increase productivity.

\section{Causal Links}

Kenkel and Ribar leave their underlying model implicit in their econometrics, but perhaps it is useful to make explicit the causal linkages by which drinking is related to earnings and marital status. Most obvious are links that, in the authors' framework, would be considered "reverse" causation, and I begin with those.

Alcohol is an ingredient of beer, wine, and spirits, the consumption of which is influenced by income. Research on the effect of income on alcoholic beverage expenditures suggests that the demand for this commodity group is normal. ${ }^{4}$ That is not the same thing as demonstrating that alcohol itself is a normal commodity, since consumers may increase the quality of their drinks rather than the quantity as their incomes increase. But it would be surprising indeed if income played no role in determining alcohol consumption.

In a consumer choice framework, it is standard to consider the wage rate rather than earnings as the relevant exogenous variable. To the extent that drinking is complementary to leisure activities, the wage rate will affect drinking both through the income effect and the laborleisure choice.

"Reverse" causation is also likely to be important in the case of marital status. A recent study, using the NLSY data, found that people tend to reduce their drinking markedly the year before getting married and to sustain this reduction during the year after marriage. ${ }^{5}$ It appears that with love comes a tendency to substitute home-oriented activities for barhopping and the like.

The causal linkages that interest Kenkel and Ribar go in the other direction, where earnings and marriage are viewed as consequences of drinking rather than the reverse. Such linkages are not plausible for moderate drinking, so the authors utilize measures of alcohol dependence, abuse, and frequency of intoxication (six drinks or more in a single occasion). "Dependence"' and "abuse' both serve as good prox-

4. Sammartino (1990).

5. Miller-Tutzauer, Leonard, and Windle (1991). 
ies for frequent drinking and frequent intoxication (see table 1), and their results may be interpreted accordingly.

Alcohol abuse may reduce earnings (wage rates or hours worked) by any of several mechanisms. In the near term, hangovers may result in absenteeism or impaired performance, while drinking during the working day may impair cognitive and physical capacity in various ways. Over the longer term frequent intoxication may result in disabling injuries or health problems and increase the chance of acquiring a police record. These same mechanisms may also be important in the marriage market, where an alcohol abuser will be a less attractive partner than an otherwise similar person who drinks moderately or abstains.

Adult drinking patterns are strongly correlated with teenage drinking, suggesting a more subtle link between drinking and earnings. In particular there is strong evidence that youthful drinking impairs the acquisition of human capital by leading to early termination of schooling. ${ }^{6}$ Although early termination of schooling and consequent entry into the labor market may initially enhance earnings, after a few years those with more schooling will tend to earn more.

\section{The Authors' Econometric Results}

Kenkel and Ribar provide an extensive array of coefficient estimates. They use several alternative estimation methods, definitions of drinking, and sets of covariates. Most of these results characterize the contemporaneous association between some measure of drinking (as a causal agent) and marital status, earnings, and hours worked (as consequences). This "shotgun" approach is consistent with best econometric practice, given uncertainty about the appropriate specification.

Kenkel and Ribar's results on marriage are quite robust. In nearly every estimate they find a negative relationship between heavy drinking (however measured) and the likelihood of being married. In most specifications the effect is significant and quite large. There appears to be an important causal effect here. But in which direction? The fact that the estimated effects are much smaller (and usually insignificant) in the simultaneous equation estimates favors an interpretation that empha-

6. Mullahy and Sindelar (1989); Cook and Moore (1993). 
sizes the reverse causal process. Love and marriage leads (at least initially) to reduced alcohol consumption for both men and women.

The results for earnings and hours are more varied, and extracting a coherent conclusion requires strong priors concerning the various specifications. A first cut comes with a judgment concerning the alternative measures of drinking. My preference is for the "heavy drinking" measure (which is the number of occasions in the previous month where the respondent consumed six or more drinks), as opposed to the measures of dependence and abuse. Heavy drinking is objective and measures directly the mechanism-intoxication-by which drinking is likely to interfere with productivity for youths.

The authors' estimated effects of heavy drinking on earnings are for the most part small and insignificant, a result that is compatible with Mullahy and Sindelar's findings for this age group. ${ }^{7}$ But in their simultaneous equation estimates, there is evidence that heavy drinking does indeed reduce productivity. The simultaneous equation estimates have an edge over the other specifications because, as explained above, there is every reason to believe that earnings influence drinking as well as the reverse. What we find in these simultaneous equation estimates is that heavy drinking reduces earnings for both men and women and in about the same proportion (although the effect is only significant for men). Because hours worked are essentially unaffected by heavy drinking for men and actually increase for women, it appears that the effect on earnings is entirely the result of a reduction in the wage rate. Thus, heavy drinking by workers in their twenties appears to limit access to high-wage jobs but does not cause any reduction in hours worked.

The finding that women, but not men, work more hours when they drink heavily, is puzzling. Rather than stretch for an ex post explanation, I would prefer to see more research on this matter. The peculiar finding may result from the selection process; only workers are included in the data set used for these estimates.

Kenkel and Ribar's estimates may understate the negative effect of heavy drinking on earnings because their specifications incorporate schooling as a covariate. That eliminates one potentially important mechanism by which a tendency to drink heavily may influence productivity over the life course. ${ }^{8}$

7. Mullahy and Sindelar (1993).

8. Cook and Moore (1993). 


\section{Further Research}

Kenkel and Ribar demonstrate the difficulty of extracting reliable estimates of a complex causal process from natural (as opposed to experimental) data. They try several stratagems to remove potential bias stemming from unobserved heterogeneity and from contemporaneous simultaneity. Because their estimates are sensitive to the method of estimation, readers' prior views concerning how drinking affects earnings may not be much revised by this exercise.

How could we hope to generate more definitive results? Some guidance in this matter comes from specifying the conceptual experiment that underlies this effort ${ }^{9}$ To the extent that we, like Irving Fisher, are interested in what can be gained by restricting the availability of alcohol, then the desired experiment is something like this: Suppose that a sample of adolescents is randomly assigned to jurisdictions that differ with respect to the stringency of alcohol control measures (tax, minimum drinking age, advertising) and other contextual determinants of drinking, and that this "treatment"' is preserved through age thirty. Will the subjects in the more stringent jurisdictions end up earning more on the average?

Several economists have produced estimates of the effects of alcohol control measures on youthful drinking and its consequences with something like this conceptual experiment in mind. ${ }^{10}$ What carries us from the conceptual experiment to the analysis of nonexperimental data is the assumption that the observed geographic variation in alcohol control measures is independent of the unobserved heterogeneity among youthful residents. Perhaps the same approach will prove productive for earnings as it has for alcohol abuse, schooling, and traffic accidents.

Alternatively, perhaps we should go back to plying typesetters with beer.

Comment by Sam Peltzman. The Kenkel-Ribar paper can be viewed as a description of behavior. It can also be viewed as part of a recipe for policy. The paper is a solid contribution to knowledge, and I have only minor reservations about it. My major reservation is about the

9. Mullahy (1993).

10. Cook and Tauchen (1982), Grossman and others (1993), and Cook and Moore (1993). 
potential misuse of the authors' results. Specifically, I believe it would be incorrect to interpret the structural equations underlying some of their findings as behavioral responses to variables amenable to policy manipulation.

We learn much about the behavior of alcoholics in this paper. Perhaps the most interesting results come from the authors' simultaneous equation model. It tells us that the quantity (not just the quality) of alcohol demanded increases with income and that more consumption lowers income. My only reservation here is the lack of much discussion of the context in which these results are obtained. Theirs is a sample of young adults. As the authors point out, these are heavy drinking years. Most of the heavy drinkers in their sample will soon be cut back substantially. This raises some obvious questions. Is the behavior Kenkel and Ribar describe permanent or temporary? Specifically, are the negative effects in income more than a matter of the timing of income flows? It is impossible to answer such questions with this database. But the unrepresentative nature of the sample has to temper any conclusions.

The time period Kenkel and Ribar study is also unrepresentative in that heavy drinking in general seemed to be going out of style in the 1980s. The decade witnessed a sharp decline in per capita hard liquor consumption, a more moderate decline in wine consumption, and a flattening of growth in beer consumption. Because the sample group uses beer especially heavily, it was less affected by the trend toward less alcohol than older devotees of hard liquor. Nevertheless, the fact that heavy drinking, like heavy smoking, was becoming less respectable or acceptable should be kept in mind in evaluating the results, especially the longitudinal analysis in table 6 . For example, one result here is that increased heavy drinking is associated with increased (male) income. This seems at odds with Kenkel and Ribar's other findings on the income effects of drinking. But it may mean only that high income males lagged in response to the pressure to reduce heavy drinking.

Kenkel and Ribar are appropriately cautious about the policy implications of their results. I want to add to that caution. They claim to have found evidence that alcohol dependence obeys the law of demand while lowering income. If this model is taken as a behavioral system, it will be tempting to reason as follows (using the authors' elasticities): If the price of alcohol is raised, say, 20 percent, then alcohol abuse will decline about 30 percent. This decline in abuse will raise average 
labor incomes by about 1 percent. " Because raising incomes is "'good," the policy implications seem clear-raise alcohol taxes.

This sort of inference would, I think, be wrong for reasons beyond those emphasized by Kenkel and Ribar-namely, the economist's usual plea to distinguish private from public gain. I agree with this, but the political process has fewer hang-ups about paternalism than economists do. The history of safety regulation, the current antismoking crusade, and so forth, make clear that an antidrinking coalition will find "alcohol taxes are good for you', an appealing slogan.

The more fundamental difficulty is with the behavioral interpretation of the model. Alcohol abuse can be viewed as an indicator of a complex set of endowments and lifestyle choices, which include dissipation of earning capacity. It also likely includes more present-orientation, less happiness, less self-confidence, and less self-control than does nonabuse. These endowments and choices are likely reflected in a myriad of consumption and investment decisions, all consistent with lowered earning capacity. The abuser-type probably eats the wrong foods, dresses poorly, has a bad temper, does not makes friends easily, etc, as well as drinks too much. Only the latter is measured in this data set. The negative coefficient of abuse in the income regression inevitably then summarizes all of the income-reducing background and decision characteristics left out of the model. The coefficient almost surely overstates the net contribution of alcohol abuse and therefore the realworld effects of an alcohol tax. Indeed, the main real-world effects of such a tax may well be simply to increase consumption of good-substitutes for alcohol, for example, other drugs or more surliness on the job, without any obvious enhancement of income.

It is easy to say that the problem I raise can be solved by a more complete model. But no workable model is likely to begin to capture the myriad of margins importantly affected by a change in the price of alcohol. The kind of evidence we would need to get at the plausible effects of an alcohol tax on income will not come from an elaboration of the authors' model. It will come from observing if income really rises after some jurisdiction substantially raises alcohol taxes.

11. Their result is that each abuser loses about -0.3 in $\ln$ earning and about 0.10 of the sample is abusers. Cutting the portion of abusers to 0.07 (that is, by 30 percent) of the sample raises the mean hourly earnings in the sample by 0.09 . 
General Discussion: The discussion was dominated by data, measurement, and modeling issues. Mark Pauly was concerned about the variables used as exogenous measures of alcohol intake. The paper's alcohol abuse and dependence variables, he noted, correspond to DSMIII definitions, which are based on the consequences of alcohol consumption, such as its effects on an individual's work. Thus, he asserted, these variables appear to have potential endogeneity problems. Pauly also argued that firms generally deal with workers who have serious drinking problems not by reducing their wages, but by terminating their employment. As a result, he said, the labor market may not accurately reffect the costs of alcohol abuse, because many abusers could be unemployed. Some portion of lost output attributable to alcohol abuse, therefore, will not be reflected in earnings data.

Noting that the paper's results suggest that, on average, single women drink more than married women, John Pencavel reminded the authors that, on average, single women work more hours than married women. Based on the equation specifications used by the authors, he suspected that the strong positive effect of alcohol consumption among women on hours worked reported in the paper is merely a reflection of the absence from the equation of a marital status variable. Donald Kenkel responded that alcohol measures are treated endogenously, and because marriage is not a regressor in the reduced form alcohol equation, alcohol consumption is not predicted based on marital status. Pencavel replied that this did not deal with the problem he raised.

Frank Wolak suggested that firms which can identify their alcoholic workers might try to pay these employees less than other workers. He argued that the authors should therefore use average hourly wages rather than earnings or hours in their regressions. Wolak also noted that younger workers tend to move in and out of the labor force, so that at any given time many have zero earnings or zero hours of work. He wondered how the authors treat this problem. Kenkel replied that the equations include only those individuals who have either positive hours worked or positive earnings. Kenkel also said that he and his co-author had estimated versions of their models corrected for selectivity bias and had found no selection effects for the earnings equations. Although there were some for the hours equations, correcting for selection did not change the alcohol coefficients, so these results are not reported in the paper. 
Robert Crandall suggested that it might be more socially acceptable for single people than married people to admit to drinking problems and argued that the resulting reporting biases may be affecting the authors' results. Admitting that reporting biases can cause a problem, Kenkel said that although the authors could not control for the bias Crandall raised, they did attempt to correct for another bias problem by using a control to indicate whether a third individual was present when a respondent was being interviewed. This control was used, Kenkel said, because it is possible that some teenage respondents would have lied about their drinking habits if their parents were present during the interview.

Given the potential effects of self-esteem on alcoholism rates, Patricia Anderson suggested that the authors add a self-esteem measure to their model. In response, David Ribar said that he and Kenkel first tried using both a self-esteem measure and a measure of internal versus external locus of control, but these variables had predictable effects without changing any of the other results.

Suzanne Scotchmer argued that the differential effects of alcohol consumption on the marriage rates of men and women may result from the fact that a higher proportion of men are alcoholics if it is also the case the alcoholic men and women tend to marry each other. If every alcoholic woman marries an alcoholic man, she explained, then the remaining alcoholic men must marry nonalcoholic women. If the marriages of double alcoholic families are more likely to dissolve than the marriages of single alcoholic ones, it will appear that alcoholism has a greater negative effect on the marriage rate of women than of men, she said.

Noting that the negative effects of alcohol abuse on earnings revealed in the paper are not as strong as those shown by previous studies, Martin Baily speculated that certain common behavioral patterns may explain these new findings. He suggested that people with a drinking problem, especially those in high-paying stressful jobs, tend to drink in the evenings. They are still able to be at their jobs the following morning, and as a result, he said, their drinking problems do not have a large effect on their employment situation. Instead, these problems affect the family, resulting, for example, in more conflict between husband and wife and, hence, in higher divorce rates.

William Niskanen asserted that the effect of alcohol consumption on 
productivity is not a sufficient basis for public policy action, which he said should be based on marginal external benefits and costs. He noted that the paper does not provide the sign of correlation between private and social costs with respect to alcohol consumption. At best, Niskanen said, the results provide guidelines for action within a paternalistic environment, in which one makes suggestions to relatives and friends. Ribar disagreed, arguing that the transmission of alcoholism from parents to children makes this issue an area of public policy concern. 


\section{References}

Amemiya, Takeshi. 1978. "The Estimation of a Simultaneous Equation Generalized Probit Model." Econometrica 46 (September): 1193-1205.

American Psychiatric Association. 1987. Diagnostic and Statistical Manual of Mental Disorders: DSM-111-R. 3d ed. rev. Washington, D.C.

Bartel, Ann, and Paul Taubman. 1986. "Some Economic and Demographic Consequences of Mental Illness." Journal of Labor Economics 4 (April): 243-56.

Becker, Gary S. 1975. Human Capital: A Theoretical and Empirical Analysis with Special Reference to Education. 2d ed. University of Chicago Press.

Becker, Gary S., and Kevin M. Murphy. 1988. "A Theory of Rational Addiction.' Journal of Political Economy 96 (August): 675-700.

Benham, Lee, and Alexandra Benham. 1982. "Employment, Earnings, and Psychiatric Diagnosis." In Economic Aspects of Health, edited by Victor R. Fuchs, 203-20. University of Chicago Press.

Berger, Mark C., and J. Paul Leigh. 1988. "The Effect of Alcohol Use on Wages." Applied Economics 20 (October): 1343-51.

Berry, Ralph E., Jr., and James P. Boland. 1977. The Economic Cost of Alcohol Abuse. The Free Press.

Center for Human Resource Research. 1990. NLS Handbook 1990: The National Longitudinal Surveys of Labor Market Experience. Ohio State University.

Chaloupka, Frank, Henry Saffer, and Michael Grossman. 1993. “Alcohol Control Policies and Motor Vehicle Fatalities." Journal of Legal Studies 31 (January): 161-86.

Cloninger, C. Robert. 1987. "Neurogenetic Adaptive Mechanisms in Alcoholism." Science, April 24, 1987, vol. 236, 410-16.

Cook, Philip J. 1981. "The Effect of Liquor Taxes on Drinking, Cirrhosis, and Auto Fatalities." In Alcohol and Public Policy: Beyond the Shadow of Prohibition, edited by Mark H. Moore and Dean R. Gerstein, 225-85. Washington, D.C.: National Academy Press.

. 1991. "The Social Costs of Drinking." In Expert Meeting on the Negative Social Consequences of Alcohol Use: Oslo, 27-31 August 1990, 49-74. Oslo: Norwegian Ministry of Health and Social Affairs.

Cook, Philip J., and Michael J. Moore. 1993. "Drinking and Schooling." Journal of Health Economics 12 (December): 411-29.

Cook, Philip J., and George Tauchen. 1982. "The Effect of Liquor Taxes on Heavy Drinking." Bell Journal of Economics 13 (Autumn): 379-90.

Fingarette, Herbert. 1988. Heavy Drinking: The Myth of Alcoholism as a Disease. University of California Press.

Fisher, Irving. 1926. Prohibition at its Worst. Macmillan. 
Frank, Richard, and Paul Gertler. 1991. "An Assessment of the Measurement Error Bias for Estimating the Effect of Mental Distress on Income.' Journal of Human Resources 26 (Winter): 154-64.

Geronimus, Arline T., and Sanders Korenman. 1992. "The Socioeconomic Consequences of Teen Childbearing Reconsidered." Quarterly Journal of Economics 107 (November): 1187-1214.

Grant, Bridget F., and others. 1991. " Prevalence of DSM-III-R Alcohol Abuse and Dependence." Alcohol Health and Research World 15 (1): 91-96.

Greenfield, Thomas K., Karen L. Graves, and Lee Ann Kaskutas. 1993. “Alcohol Warning Labels for Prevention." Alcohol Health and Research World 17 (1): 67-75.

Griliches, Zvi. 1979. "Sibling Models and Data in Economics: Beginnings of a Survey." Journal of Political Economy 87 (October): S37-S64.

Griliches, Zvi, and Jerry A. Hausman. 1986. "Errors in Variables in Panel Data." Journal of Econometrics 31 (February): 93-118.

Grossman, Michael. 1988. "Health Economics of Prevention of Alcohol-Related Problems." Paper presented at the Workshop on Health Economics of Prevention and Treatment of Alcohol-Related Problems. National Institute on Alcohol Abuse and Alcoholism, Washington, D.C., September 29-30.

. 1993. "The Economic Analysis of Addictive Behavior." In Economics and the Prevention of Alcohol-Related Problems: Proceedings of a Workshop in Economic and Socioeconomic Issues in the Prevention of AlcoholRelated Problems, edited by Gregory Bloss and Michael E. Hilton, 91-123. Rockville, Md.: National Institute on Alcohol Abuse and Alcoholism, U.S. Department of Health and Human Services.

Grossman, Michael, and others. 1993. "Effects of Alcohol Price Policy on Youth." Working Paper 4385. Cambridge, Mass.: National Bureau of Economic Research. June.

Harwood, Henrick J., and others. 1984. Economic Costs to Society of Alcohol and Drug Abuse and Mental Illness: 1980. Research Triangle Park, N.C.: Research Triangle Institute.

Heien, Dale M., and David J. Pittman. 1989. "The Economic Costs of Alcohol Abuse: An Assessment of Current Methods and Estimates." Journal of Studies on Alcohol 50 (November): 567-79.

- 1993. "The External Costs of Alcohol Abuse." Journal of Studies on Alcohol 54 (May): 302-7.

Hesselbrock, Victor M. 1986. "Family History of Psychopathology in Alcoholics: A Review and Issues." In Psychopathology and Addictive Disorders, edited by Roger E. Meyer, 41-56. New York: Guilford Press.

Hoyt, Gail Mitchell, and Frank J. Chaloupka. 1993. "Self-Reported Substance Use and Survey Conditions: An Examination of the National Longitudinal Survey of Youth." Paper presented at the meetings of the Western Economic Association International, Lake Tahoe, Nev., June. 
Kaestner, Robert. 1991. "The Effect of Illicit Drug Use on the Wages of Young Adults.' Journal of Labor Economics 9 (October): 381-412.

Kenkel, Donald S. 1991a. "Health Behavior, Health Knowledge, and Schooling." Journal of Political Economy 99 (April): 287-305.

_. 1991b. “What You Don't Know Really Won't Hurt You.' Journal of Policy Analysis and Management 10 (Spring): 304-9.

. 1993. "Drinking, Driving, and Deterrence: The Effectiveness and Social Costs of Alternative Policies." Journal of Law and Economics 36 (October): 877-913.

Klein, Hugh, and David J. Pittman, 1990. "Drinker Prototypes in American Society." Journal of Substance Abuse 2: 299-316.

Korenman, Sanders, and David Neumark. 1991. "Does Marriage Really Make Men More Productive?' Journal of Human Resources 26 (Spring): 282307.

1992. "Marriage, Motherhood, and Wages." Journal of Human Resources 27 (Spring): 233-55.

Maddala, G.S. 1983. Limited-Dependent and Qualitative Variables in Econometrics. Cambridge: Cambridge University Press.

1987. “'Limited Dependent Variable Models Using Panel Data." Journal of Human Resources 22 (Summer): 307-38.

Manning, Willard G., and others. 1991. The Costs of Poor Health Habits. Harvard University Press.

Miller-Tutzauer, Carol, Kenneth E. Leonard, and Michael Windle. 1991. "Marriage and Alcohol Use: A Longitudinal Study of 'Maturing Out'.", Journal of Studies on Alcohol 52 (September): 434-40.

Mincer, Jacob. 1974. Schooling, Experience, and Earnings. National Bureau of Economic Research.

Miron, Jeffrey A., and Jeffrey Zwiebel. 1991. "Alcohol Consumption During Prohibition." American Economic Review Papers and Proceedings 81 (May): 242-47.

Mullahy, John. 1993. "Alcohol and the Labor Market." In Economics and the Prevention of Alcohol-Related Problems: Proceedings of a Workshop in Economic and Socioeconomic Issues in the Prevention of Alcohol-Related Problems, edited by Gregory Bloss and Michael E. Hilton, 141-74. Rockville, Md.: National Institute on Alcohol Abuse and Alcoholism, U.S. Department of Health and Human Services.

Mullahy, John, and Jody Sindelar. 1989. "Life-Cycle Effects of Alcoholism on Education, Earnings, and Occupation." Inquiry 26 (Summer): 272-82.

- 1991. "Gender Differences in Labor Market Effects of Alcoholism." American Economic Review Papers and Proceedings 81 (May): 161-65.

partment of Economics, Trinity College, Hartford, Conn. Mimeo. 
1993. “Alcoholism, Work, and Income." Journal of Labor Economics 11 (July): 494-520.

Phelps, Charles E. 1987. "Risk and Perceived Risk of Drunk Driving Among Young Drivers." Journal of Policy Analysis and Management 6 (Summer): 708-14.

Pogue, Thomas F., and Larry G. Sgontz. 1989. "Taxing to Control Social Costs: The Case of Alcohol."' American Economic Review 79 (March): 23543.

Ribar, David. 1994. "Teenage Fertility and High School Completion." Review of Economics and Statistics (forthcoming).

Rice, Dorothy. 1993. "The Economic Cost of Alcohol Abuse and Alcohol Dependence, 1990." Alcohol Health and Research World 17 (1): 10-11.

Rice, Dorothy P., and others. 1990. The Economic Costs of Alcohol and Drug Abuse and Mental Illness: 1985. DHHS Publication No. (ADM) 90-1694. Alcohol, Drug Abuse, and Mental Health Administration, Public Health Service, U.S. Department of Health and Human Services.

Sammartino, Frank. 1990. Federal Taxation of Tobacco, Alcoholic Beverages, and Motor Fuels. Congressional Budget Office.

Schepers, Andreas, and Gerhard Arminger. 1992. MECOSA User Guide. Frauenfeld, Switzerland: Systeme für Logistik und Informationstechnik.

Shaper, A. Gerald. 1993. "Editorial: Alcohol, the Heart, and Health." American Journal of Public Health 83 (June): 799-801.

Sindelar, Jody. 1993. "Measurement Issues in Alcohol Survey Data." In Economics and the Prevention of Alcohol-Related Problems: Proceedings of a Workshop in Economic and Socioeconomic Issues in the Prevention of Alcohol-Related Problems, edited by Gregory Bloss and Michael E. Hilton, 201-28. Rockville, Md.: National Institute on Alcohol Abuse and Alcoholism, U.S. Deparment of Health and Human Services.

Snortum, John R., Dale E. Berger, and Ragnar Hauge. 1989. "Legal Knowledge and Compliance: Drinking and Driving in Norway and in the United States." Alcohol, Drugs, and Driving 4 (3-4): 251-63.

USDHHS (U.S. Department of Health and Human Services; Public Health Service; Alcohol, Drug Abuse, and Mental Health Administration). 1990. Seventh Special Report to the U.S. Congress on Alcohol and Health from the Secretary of Health and Human Services. DHHS Publication No. (ADM) 90-1656.

Zucker, Robert A., and Edith S. Lisansky Gomberg. 1986. "Etiology of Alcoholism Reconsidered: The Case for a Biopsychosocial Process." American Psychologist 41 (July): 783-93. 